\title{
Unraveling the complexity of transcriptomic, metabolomic and quality environmental response of tomato fruit
}

\author{
Daniela D'Esposito ${ }^{1}$, Francesca Ferriello ${ }^{1}$, Alessandra Dal Molin², Gianfranco Diretto ${ }^{3}$, Adriana Sacco 1 ,

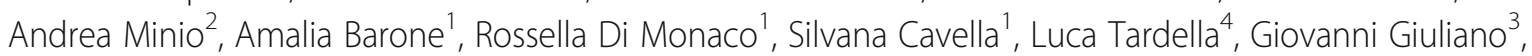 \\ Massimo Delledonne ${ }^{2}$, Luigi Frusciante ${ }^{1}$ and Maria Raffaella Ercolano ${ }^{1 *}$
}

\begin{abstract}
Background: The environment has a profound influence on the organoleptic quality of tomato (Solanum lycopersicum) fruit, the extent of which depends on a well-regulated and dynamic interplay among genes, metabolites and sensorial attributes. We used a systems biology approach to elucidate the complex interacting mechanisms regulating the plasticity of sensorial traits. To investigate environmentally challenged transcriptomic and metabolomic remodeling and evaluate the organoleptic consequences of such variations we grown three tomato varieties, Heinz 1706, whose genome was sequenced as reference and two "local" ones, San Marzano and Vesuviano in two different locations of Campania region (Italy).

Results: Responses to environment were more pronounced in the two "local" genotypes, rather than in the Heinz 1706. The overall genetic composition of each genotype, acting in trans, modulated the specific response to environment. Duplicated genes and transcription factors, establishing different number of network connections by gaining or losing links, play a dominant role in shaping organoleptic profile. The fundamental role of cell wall metabolism in tuning all the quality attributes, including the sensorial perception, was also highlighted.
\end{abstract}

Conclusions: Although similar fruit-related quality processes are activated in the same environment, different tomato genotypes follow distinct transcriptomic, metabolomic and sensorial trajectories depending on their own genetic makeup.

Keywords: Environment, Fruit quality, Metabolome, Network, Plasticity, Sensorial attributes, Solanum lycopersicum, Transcriptome

\section{Background}

Tomato (Solanum lycopersicum) is one of the most popular and widely consumed vegetable crops worldwide and its peculiar fruit quality properties can be strong modified by environmental conditions. The response to different environmental conditions depends on several factors, including the genetic diversity and genome plasticity of individual genotypes. Both the occurrence and magnitude of phenotypic plasticity for any trait are themselves characteristics that are under genetic control,

\footnotetext{
* Correspondence: ercolano@unina.it

${ }^{1}$ Department of Agricultural Sciences, University of Naples Federico II, Portici 80055, Italy

Full list of author information is available at the end of the article
}

with levels varying between traits, individuals and populations [1-5]. Thus, differences in functional traits are predictive of differences in individual genomic responses to environmental changes, albeit this has rarely been experimentally tested in the field [6]. Trait variation among individuals must be considered when evaluating the importance of functional traits as a predictor of how a genotype will respond to environmental change [7]. Indeed, the role of such plasticity could be crucial for buffering the detrimental effects of environmental changes $[8,9]$. A proposed hypothesis is that phenotypic plasticity can be favored by gene duplication events, which generate redundant genomic functions that may diverge over time [10]. 
The organoleptic properties of tomato fruit are defined by a set of sensory attributes, such as flavor, fruit appearance and texture. Flavor is defined as the combination of taste and odor. Intense taste is the result of an increase in gluconeogenesis, hydrolysis of polysaccharides, a decrease in acidity and accumulation of sugars and organic acids [11], while aroma is produced by a complex mixture of volatile compounds and degradation of bitter principles, flavonoids, tannins and related compounds $[11,12]$. Fruit color is mainly determined by carotenoids and flavonoids [13, 14], while textural characteristics are primary controlled by the cell wall structure in addition to cuticle properties, cellular turgor and fruit morphology [15]. In last years, tomato fruit organoleptic quality has been investigated both at the genetic and biochemical levels in order to obtain new varieties with improved taste [16-19]. Recently, the genomes of traditional tomato cultivars such as San Marzano (SM) and Vesuviano (RSV), considered important models for fruit quality parameters, have been sequenced [20]. SM, originating from the Agro Sarnese-Nocerino area in southern Italy, produces elongated fruits with a peculiar bittersweet flavor [21]. RSV, originating from the volcanic slopes of Vesuvius in the same region, produces small sweet pear-shaped fruits that are suitable for longterm storage thanks to their texture [22].

The ability to dissect genomic and metabolic responses to environmental cues is key to understanding the molecular basis of plasticity of fruit quality traits. In spite of the large amount of information on the genomic and metabolomic components controlling fruit quality traits, very little is known to date regarding the transcriptional dynamics (plasticity) controlling such traits. A systems biology approach, integrating different -omics datasets, is instrumental for elucidating complex mechanisms controlling organoleptic properties [23].

The aim of this work was to quantify the extent of the transcriptional response to environmental cues, to measure the metabolic activity and to evaluate the organoleptic consequences of the genome variation identified. We used a multilevel (system biology) approach combining genome, transcriptome, metabolome and sensorial data of three tomato varieties, Heinz $1706(\mathrm{H})$, SM and RSV, grown in two different localities.

\section{Methods}

\section{Plant material and growth conditions}

H, SM and RSV tomato (Solanum lycopersisum) plants were cultivated in two locations in southern Italy, Sarno (province of Salerno, SA) and Acerra (province of Naples, NA) characterized by Mediterranean climate with lower average air temperature $(\mathrm{T})$ and humidity $(\mathrm{U})$ and slight higher average number of rainy days $(R)$ in Acerra $\left(\mathrm{T}=22.7 \mathrm{C}^{\circ} ; \mathrm{U}=63.8 \% ; \mathrm{R}=6.6\right.$ days $)$ than in
Sarno ( $\mathrm{T}=23.8 \mathrm{C}^{\circ} ; \mathrm{U}=72.9 \% ; \mathrm{R}=4.5$ days $)$ during the growing season (http://www.ilmeteo.it/portale/archiviometeo). Differences between the two locations also regarded soil texture, characterized by predominance of silt and clay in Acerra (Ac) limestone and sand in Sarno (Sa). In addition, differences in chemical parameters such as $\mathrm{pH}$ (7.3 in Acerra, 8.3 in Sarno), limestone (absent in Acerra, $10 \mathrm{~g} / \mathrm{Kg}$ in Sarno) exchangeable magnesium $(0,94 \mathrm{meq} / 100 \mathrm{~g}$ in Acerra, $2.16 \mathrm{meq} / 100 \mathrm{~g}$ in Sarno) exchangeable potassium, (4.55 meq/100 $\mathrm{g}$ in Acerra, $1.93 \mathrm{meq} / 100 \mathrm{~g}$ in Sarno), ratio C/N (8.2 g/Kg in Acerra, $11.1 \mathrm{~g} / \mathrm{Kg}$ in Sarno) and electrical conductivity (1:5) (0.07 $\mathrm{dS} / \mathrm{m}$ in Acerra, $0.237 \mathrm{dS} / \mathrm{m}$ in Sarno) were found between the two fields.

The genotypes were grown in a randomized design during the summer of 2012 following the tomato field procedures used for the area. Young seedlings ( one month old) were planted at the end of April in two blocks, divided into three plots. In each plot 3-4 plants of any variety were allocated.

At mature ripe stage (according to the full appearance of red color on the fruit surface, Additional file 1: Figure S1) fruits were collected from the intermediate trusses of the plant. In each plot fruits belonging to the same variety were pooled. The six samples obtained for each variety was used to conduct the sensory evaluation. The rest was chopped, divided into replica aliquots and immediately frozen under liquid nitrogen and then stored at $-80^{\circ}$.

\section{RNA sequencing and differential expression analysis}

Total RNA used for downstream RNA sequencing and qPCR validation was extracted from frozen, homogenized, and powdered fruit tomato samples following the protocol previously described [24]. RNA quality was checked with an Agilent Bioanalyzer 2100. Six RNA-seq libraries were prepared starting from $2.5 \mu \mathrm{g}$ of total RNA using the TruSeq RNA Sample Prep Kit v2 (Illumina Inc., San Diego, CA, USA). The libraries were then size-selected with a Pippin Prep (Sage Science Inc., Beverly, MA, USA) resulting in a selected range of about 250-350 bp. The cDNA libraries were sequenced with TruSeq Sequencing by means of a Synthesis Kit v3-HS and TruSeq Paired End Cluster Kit v3-cBot-HS (Illumina Inc., San Diego, CA, USA) using an HiSeq 1000 (Illumina Inc., San Diego, CA, USA) sequencer according to the manufacturer's instructions to generate 100-bp paired-end reads. Sequencing reads were analyzed with CASAVA software (Illumina Inc., San Diego, CA, USA) for demultiplexing and FASTQ file generation. The quality of reads was checked using RseQC software [25].

RNAseq reads were aligned on S. lycopersicum cv. Heinz 1706 version 2.40 genome, San Marzano and Vesuviano [20] respective genome using TopHat (ver. 2.0.6). Transcriptome reconstruction and identification 
of differentially expressed genes (DEGs) and isoforms (DEI) for module of $\log$ in base 2 fold change (FC) values were performed with Cufflinks (ver2.1.1) using multi-read correction. This pipeline was followed for each cultivar and with respective reference annotation to guide a Reference Annotation Based Assembly (RABT) to allow the detection of novel genes/isoforms [26, 27].

Real-time quantitative RT-PCR was performed using $1 \mu \mathrm{g}$ of total RNA reverse transcribed with the Transcriptor High Fidelity cDNA Synthesis Kit, Roche. Amplification was carried out with a 7900HT Fast Real-Time PCR System (Applied Biosystems) using Power SYBR ${ }^{\circ}$ Green Master Mix (Applied Biosystems). There were $25 \mu \mathrm{l}$ of reaction mixture containing: $0.5 \mu \mathrm{M}$ of each primer and $12.5 \mu \mathrm{l}$ of SYBR GreenPCR master mix. Relative quantification was achieved by the $\Delta \Delta C_{\mathrm{T}}$ method [28]. The list of primers used is reported in Additional file 1: Table S1.

\section{DEG functional classification, GO enrichment analysis and gene copy number detection}

Functional annotation of novel genes was performed via Blast2GO [29]. Plant MetGenMAP [30] was used to perform GO enrichment analysis at p-value cut-off of 0.05 after Bonferroni correction. MapMan software [31] was used for the pathway visualization of the DEGs and DEIs. Fold changes (FC) of the genes in the enriched GO categories of interest were plotted in a frequency distribution table, based on the frequency with which they were detected in each GO category. Genes with FC falling outside the $90 \%$ boundaries of this frequency distribution were considered "outliers". In order to identify multy copy gene families a local blast database of all Heinz 1706, San Marzano and Vesuviano genes was built and the DEGs between the two locations for each genotype were subjected to a BLASTN search on the respective database to identify homologous genes using a 1e-30 e-value threshold and nucleotide identity greater than $72 \%$. The analysis was refined to keep blast results for which the query coverage per subject was greater than $50 \%$.

\section{Metabolome analysis}

Liquid chromatography-electrospray ionization- mass spectrometry (LC-ESI-MS) analysis of the fruit semipolar metabolome was performed as previously described [32, 33] with slight modifications: $25 \mathrm{mg}$ of freeze-dried, homogenized tomato fruit powder were extracted with $0.75 \mathrm{ml}$ cold $75 \%(\mathrm{v} / \mathrm{v})$ methanol, $0.1 \%(\mathrm{v} / \mathrm{v})$ formic acid, spiked with $10 \mu \mathrm{g} \mathrm{ml}-1$ formononetin. After shaking for $40 \mathrm{~min}$ at $20 \mathrm{~Hz}$ using a Mixer Mill 300 (Qiagen), samples were centrifuged for $15 \mathrm{~min}$ at $20,000 \mathrm{~g}$ at $4{ }^{\circ} \mathrm{C} ; 0.6 \mathrm{ml}$ of supernatant were removed and transferred to HPLC tubes. For each genotype, at least two independent extractions from three independent pools were performed. LC-
MS analyses were carried out using a LTQ-Orbitrap Discovery mass spectrometry system (Thermo Fisher Scientific) operating in positive electrospray ionization (ESI), coupled to an Accela U-HPLC system (Thermo Fisher Scientific, Waltham, MA). Liquid chromatography was carried out using a Phenomenex C18 Luna column $(150 \times$ $2.0 \mathrm{~mm}, 3 \mu \mathrm{m})$. The mobile phase was composed by water $-0.1 \%$ formic acid (A) and acetonitrile $-0.1 \%$ formic acid (B). The gradient was: $95 \% \mathrm{~A}: 5 \% \mathrm{~B}$ (one minute), a linear gradient to $25 \% \mathrm{~A}: 75 \% \mathrm{~B}$ over $40 \mathrm{~min}, 2 \mathrm{~min}$ isocratic, before going back to the initial LC conditions in $18 \mathrm{~min}$. Ten $\mu \mathrm{l}$ of each sample were injected and a flow of $0.2 \mathrm{ml}$ was used throughout the LC runs.. Detection was carried out continuously from 230 to $800 \mathrm{~nm}$ with an online Accela Surveyor photodiode array detector (PDA, Thermo Fisher Scientific, Waltham, MA). Metabolites were quantified in a relative way by normalization on the internal standard amounts. ESI-MS ionization was performed using the following parameters: capillary voltage and temperature were set at $25 \mathrm{~V}$ and $300{ }^{\circ} \mathrm{C}$; sheath and aux gas flow rate at, respectively, 40 and 25 . Spray voltage was set to $4 \mathrm{kV}$ and tube lens at $90 \mathrm{~V}$. Metabolite identification was performed by comparing chromatographic and spectral properties with standards and reference spectra at the Pubchem database (http://pubchem.ncbi.nlm.nih.gov/) or the Metabolomics Fiehn Lab Mass Spectrometry Adduct Calculator (http://fiehnlab.ucdavis.edu/staff/kind/Metabolomics/MS-Adduct-Calculator/). Liquid chromatography -Atmospheric pressure chemical ionization- mass spectrometry (LC-APCI-MS) analysis of fruit isoprenoids was performed as previously described [34].

\section{Sensorial analysis}

Sensorial analyses were performed by a trained panel of six judges. For each variety in the two environments, twelve attributes were evaluated: two related to appearance (red color, color uniformity), five to flavor (sourness, saltiness, sweetness, flavor, odor), five to texture (flouriness, hardness, turgidity, juiciness, and skin resistance). Each panelist received three samples; then the panel rated the different parameters on a $0-10$ scale. Analysis of variance (ANOVA) was used to identify significant variation in quality attributes between environments. Principal component analysis (PCA) was used to explore the relationship between sensorial attributes and to ascertain the variability of the sensory characteristics of Acerra and Sarno. Sensory profiles were analyzed to assess the effects of genotype, environment, and their interactions by twoway ANOVA.

\section{Network analysis}

Pearson's correlation coefficients were calculated for selected SM and RSV data points represented by all the sensorial attributes, DEGs related to fruit quality and 
changed metabolites between the two environments (Additional file 2: Dataset S1-S4). All the data were normalized against the control represented by Heinz1706. Positive and negative correlations $>0.8$ and $<-0.8$ were considered for the construction of a dynamic network and visualized with Cytoscape version 3.2.1 [35].

\section{Results}

\section{Transcriptome sequencing and assembly}

RNA-Seq libraries from three tomato (Solanum lycopersicum) varieties (H, SM and RSV), grown in two locations in the southern Italian region Campania, namely at Sarno (Sa) and Acerra (Ac), were sequenced using Illumina technology, obtaining an average of 39.7 millions of fragments per sample (Additional file 1: Table S2). H, SM and RSV reads were mapped to the respective genome assemblies. The three varieties showed more than 19,000 expressed genes on average, 17,382 of which were previously annotated and shared among the three plus an average of 2,255 novel loci for variety (Table 1). Overall, the transcripts obtained showed a mean length of 1,852 base pairs (bp) and a mean N50 of 2,475 bp (Table 1). Functional annotation of novel genes allowed at least one Gene Ontology (GO) term to be assigned to $20 \%$ of the novel genes identified in the reference genome SL2.40, to $8 \%$ of SM novel genes and to $10 \%$ of RSV novel genes (Additional file 2: Dataset S5, S6 and S7).

\section{Extent of gene expression variation in three tomato cultivars}

The three varieties, H, SM and RSV, expressed, respectively, a total of 20,164, 19,680 and 19,590 transcripts in both localities. The $\mathrm{H}$ variety specifically expressed a core set of 993 genes, instead 615 and 669 genes were expressed in SM and in RSV respectively (Additional file 1: Figure S2). Differentially expressed genes (DEGs) for each genotype (H, SM and RSV) were computed comparing the expression levels in the two different environments (Ac and Sa). Figure 1a reports the number of genes that showed differential expression in $\mathrm{H}$ (595), in SM (801) and RSV (864). Interestingly, most of the highly expressed DEGs were related to fruit quality in all

Table 1 Transcriptome reconstruction statistics for Heinz 1706, San Marzano and Vesuviano cultivars

\begin{tabular}{llll}
\hline & $\begin{array}{l}\text { Heinz } \\
1706\end{array}$ & $\begin{array}{l}\text { San } \\
\text { Marzano }\end{array}$ & Vesuviano \\
\hline Known genes (SL2.40) & 34,725 & 34,725 & 34,724 \\
(transcripts) & $(38,295)$ & $(38,249)$ & $(38,243)$ \\
Novel loci (transcripts) & 2,261 & 2,309 & 2,195 \\
& $(3,242)$ & $(3,365)$ & $(3,250)$ \\
Maximum length of transcripts & 242,963 & 243,000 & 243,266 \\
N50 length of transcripts & 2,394 & 2,511 & 2,522 \\
Mean length of transcripts & $1,784.85$ & $1,864.37$ & $1,883.92$ \\
\hline
\end{tabular}

genotypes (Fig. 1b, c, and d). Fruit quality genes showing structural variants in SM and RSV [20] were also investigated. Of 2,051 genes showing variants both in RSV and $\mathrm{SM}$ in comparison to $\mathrm{H}, 78$ and 89 genes were differentially expressed in SM and RSV, respectively, including a large number of genes encoding transcription factors/regulators. Of 626 and 184 genotype-specific genes with variants in SM and RSV, 24 and 9 genes proved to be differentially expressed in the two genotypes. The DEGs with variants in SM were predominantly represented by cell wall enzymes (xyloglucan endotransglucosylase/hydrolase, glycosyltransferase, etc.) while in RSV by transcription factors (bZIP, MYB etc., Additional file 1: Table S3).

\section{Investigations of DEGs involved in fruit quality determination}

An enrichment analysis was performed to identify Gene Ontology (GO) terms over-represented in each genotype irrespective of the environment $(G)$, in each environment irrespective of the genotype $(E)$ and in specific genotype $\times$ environment combinations $(\mathrm{G} \times \mathrm{E})$, following the scheme shown in Fig. 2a. The complete lists of GO terms enriched in the three comparisons are reported in Additional file 2: Dataset S8-S13.

Over-represented GO terms related to the environment are shown in Fig. 2b. Acerra-specific enriched GO terms were related to cell wall, ethylene and aspartate family amino acids while in Sarno to carbohydrate catabolism, serine family amino acid metabolism and amine metabolism.

Figure 2c and Additional file 1: Figure S5 show SM, $\mathrm{SM} \times \mathrm{Ac}$ and $\mathrm{SM} \times \mathrm{Sa}$ enriched GO terms related to fruit quality. Most of the SM enriched GO terms were related to amino acid and organic acid metabolism. It was noteworthy that although the two environments shared enriched GO terms, specific sections within the general metabolism were mobilized in each $\mathrm{G} \times \mathrm{E}$ interaction. For instance, $\mathrm{SM} \times$ Ac over-represented $\mathrm{GO}$ terms referring to amino acid metabolism were related to aromatic and aspartate amino acid families, while $\mathrm{SM} \times \mathrm{Sa} \mathrm{GO}$ pertained to serine family.

Additional file 1: Figures S3, S4 and S5 show $\mathrm{H}$ and RSV enriched GO terms related to amino acid, ethylene metabolism and cell wall and carbohydrate metabolism. Within each enriched GO term category, approximately $10 \%$ of genes with fold change (FC) values falling in the tail of frequency distribution, were labeled as "outliers" between the two locations (Fig. 3a and b, right). This occurrence allowed us to identify and catalogue genotype plastic genes (Additional file 1: Tables S4, S5 and S6). SM outlier genes included cell wall genes, mainly xyloglucan endotransglycosylase hydrolases (XTHs) and pectinesterases, and amino acid related genes such as decarboxylases and chlorophyll-binding proteins (Fig. 3a and b, left). 


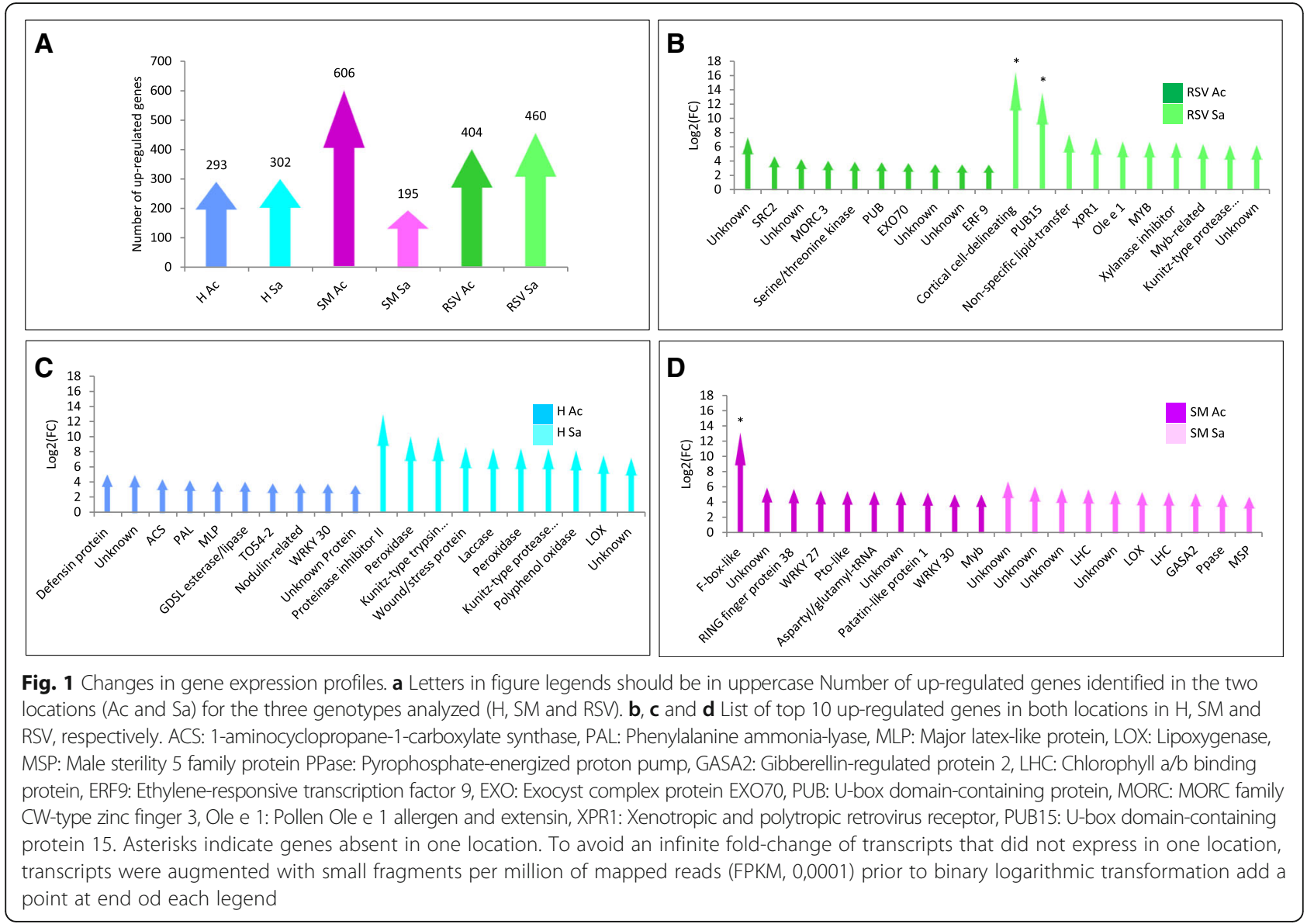

\section{Transcription-regulated processes and gene copy number variation}

The number of DEGs involved in the transcriptional and post-translation was higher in Acerra for all three genotypes, with SM showing the highest number of genes (Fig. 4a and b). Differentially expressed novel isoforms (DEIs) and alternative splicing (AS) events between the two locations were also identified (Fig. 4c and d, Additional file 1: Figure S6). In particular, differentially expressed isoforms related to cellulose biosynthesis were evidenced both in SM and RSV (Fig. 4d). Moreover in H 232 DEGs (39\%) were members of multi-copy gene families, in SM, 269 (33\%), and in RSV, 316 (36\%) (Additional file 1: Figure S7A). Most multi-copy families contained two to three copies with up to 13 copies in $\mathrm{H}$ and $\mathrm{SM}$ and up to 23 copies in RSV (Additional file 1: Figure S7B). GO categories related to fruit quality included 155,145 and $140 \mathrm{DE}$ genes, present in at least two copies, in SM, RSV and H, respectively. Genes belonging to XTH family such as Solyc03g093110 and Solyc03g093120 displayed six copies with high similarity while Solyc03g093080 and Solyc03g093130 five copies (Additional file 1: Figure S7C).

\section{Environmental effects on metabolomics profile}

The metabolite composition of $\mathrm{H}, \mathrm{SM}$ and RSV was clearly modulated by the environment and genotype (Fig. 5a). Fifty-eight, 105 and 93 metabolites showed significant differences between the two environments in $\mathrm{H}$, SM and RSV respectively (Fig. 5b, Additional file 2: Dataset S14-S15). H produced 14 metabolites at higher level in Acerra and 44 in Sarno, SM showed a pronounced metabolite abundance in Sarno (101) while RSV revealed 32 and 61 metabolites synthesized at higher level in Acerra and Sarno, respectively (Fig. 5b). The number of differentially regulated metabolites between genotypes ( $\mathrm{H}$ vs. SM, H vs. RSV and RSV vs. SM) in each location is shown in Additional file 1: Figure S8. In SM, secondary metabolites (alkaloids, phenylpropanoids, some carotenoids such as lutein, $\beta$ - and $\delta$ carotene), vitamins and many amino acids exhibited a significant increase in Sarno (Fig. 6). In $\mathrm{H}$ a higher level of sugars and of nucleic acid precursor metabolites (adenine, adenosine, guanine) in Acerra and of some alkaloids (tomatidine, hydroxy-tomatine, kukoamine C, etc.) in Sarno was noticed (Additional file 1: Figure S9). In RSV, sugars and most of organic acids were increased in Acerra and amino acids, most of alkaloids, phenylpropanoids and 


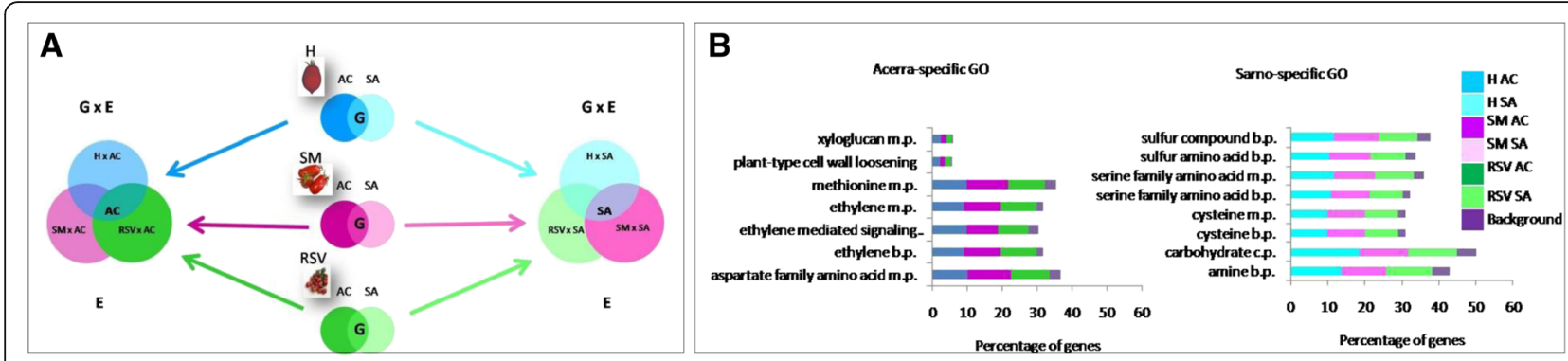

C
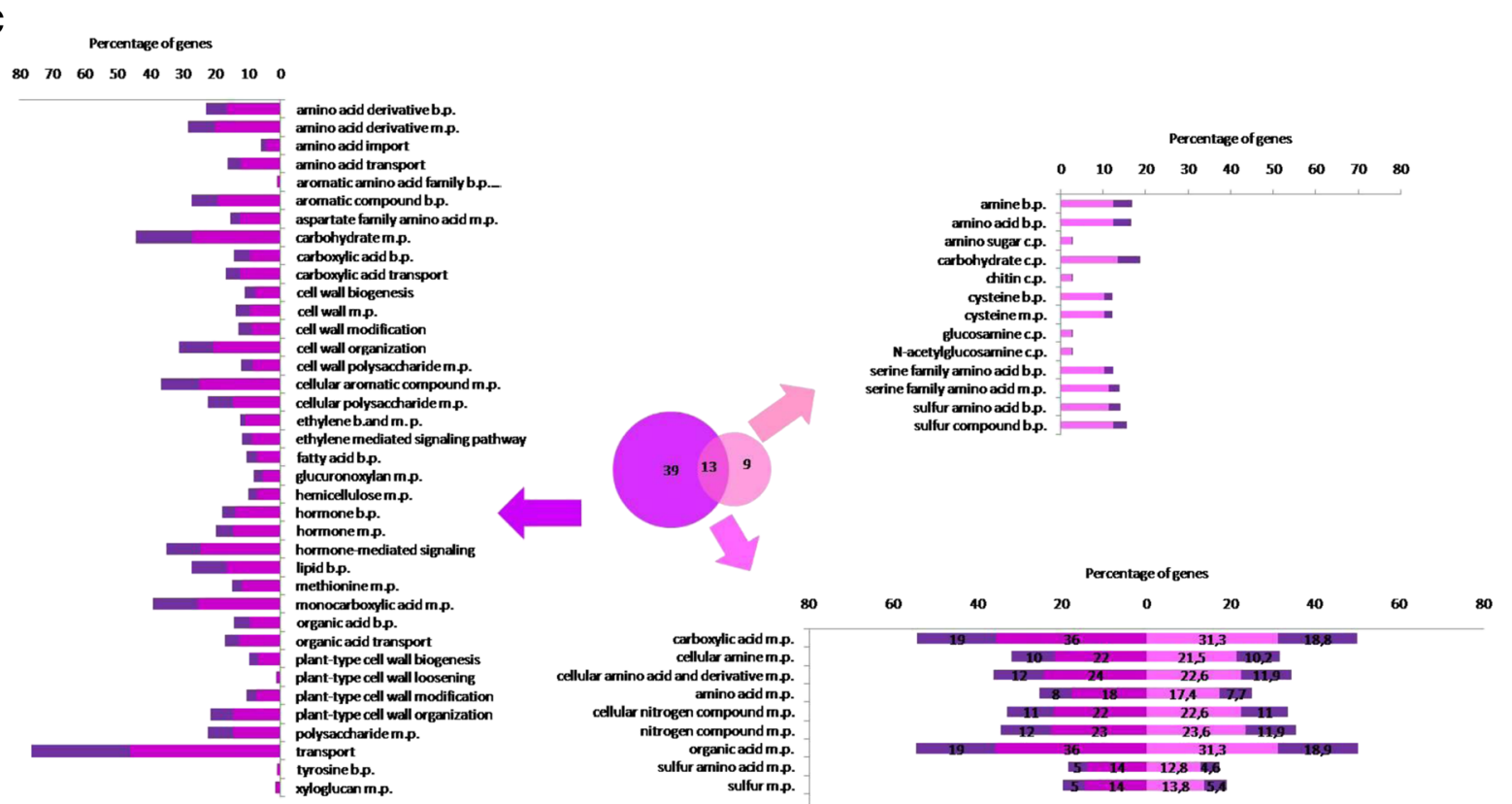

Fig. 2 Gene ontology enrichment analysis. a Scheme for classifying over-represented gene classes. For each genotype Acerra-specific (Ac) and Sarno-specific (Sa) enriched GO terms were identified. Enriched GO terms common to both environments (G) in each genotype (H, SM and RSV) were also identified. By crossing enriched GO terms in Acerra from all three genotypes, Acerra-specific and Acerra $\times$ Genotype interactions were identified. The same scheme was used to identify Sarno-specific enriched GO terms as well as Sarno $\times$ Genotype interactions. b Environmentspecific enriched GO categories. Left) Acerra-specific enriched GO terms. Right) Sarno-specific enriched GO terms. c San Marzano GO Enrichment Analysis. The Venn diagram shows common and specific enriched $\mathrm{GO}$ terms. Bar plots reflect the percentage of genes in the enriched categories of the San Marzano Acerra (left), Sarno (right) and common (below), as well as the percentage of genes belonging to the same categories in tomato genome. Common enriched GO categories are reported for both environments because some categories, although enriched in both conditions, have a different percentage of genes. $\mathrm{m}$. p. $=$ metabolic process, b.p. $=$ biological process, c.p. $=$ catabolic process

early carotenoids (phytoene, phytofluene and $\zeta$-carotene) in Sarno (Additional file 1: Figure S10). Metabolite responses to the two environments were even more genotype-specific than transcriptional ones: of the 41 metabolites up-regulated in Acerra with respect to Sarno, 33 $(80.5 \%)$ were genotype specific (Fig. 5c, left). This trend was evident, albeit to a lesser extent, for metabolites upregulated in Sarno with respect to Acerra: of the 132 metabolites up-regulated in this location, 76 (57.6\%), were genotype-specific (Fig. 5c, right). We also attempted to identify the major metabolites responsible for the separation of the two environments. Principal component analysis (PCA, Fig. 5d) revealed that for $\mathrm{H}$, adenosine, anthranilic acid and sucrose were responsible for the major difference between Acerra and Sarno; for SM, glutamic acid, glutamine, 5-oxoproline and tryptophan were the main drivers of the separation between the two environments; for RSV, phenylalanine, 5-oxoproline, sucrose, aconitic acid and leucine have discrimination power between the two environments.

\section{Assessment of fruit sensory profiles}

In order to gain further insight into the mechanisms that regulate fruit organoleptic quality traits in tomato, a sensory analysis on ripe fruits harvested in the two fields was performed through descriptive profiling. Two way analysis of variance (ANOVA, Additional file 1: Table S7) 


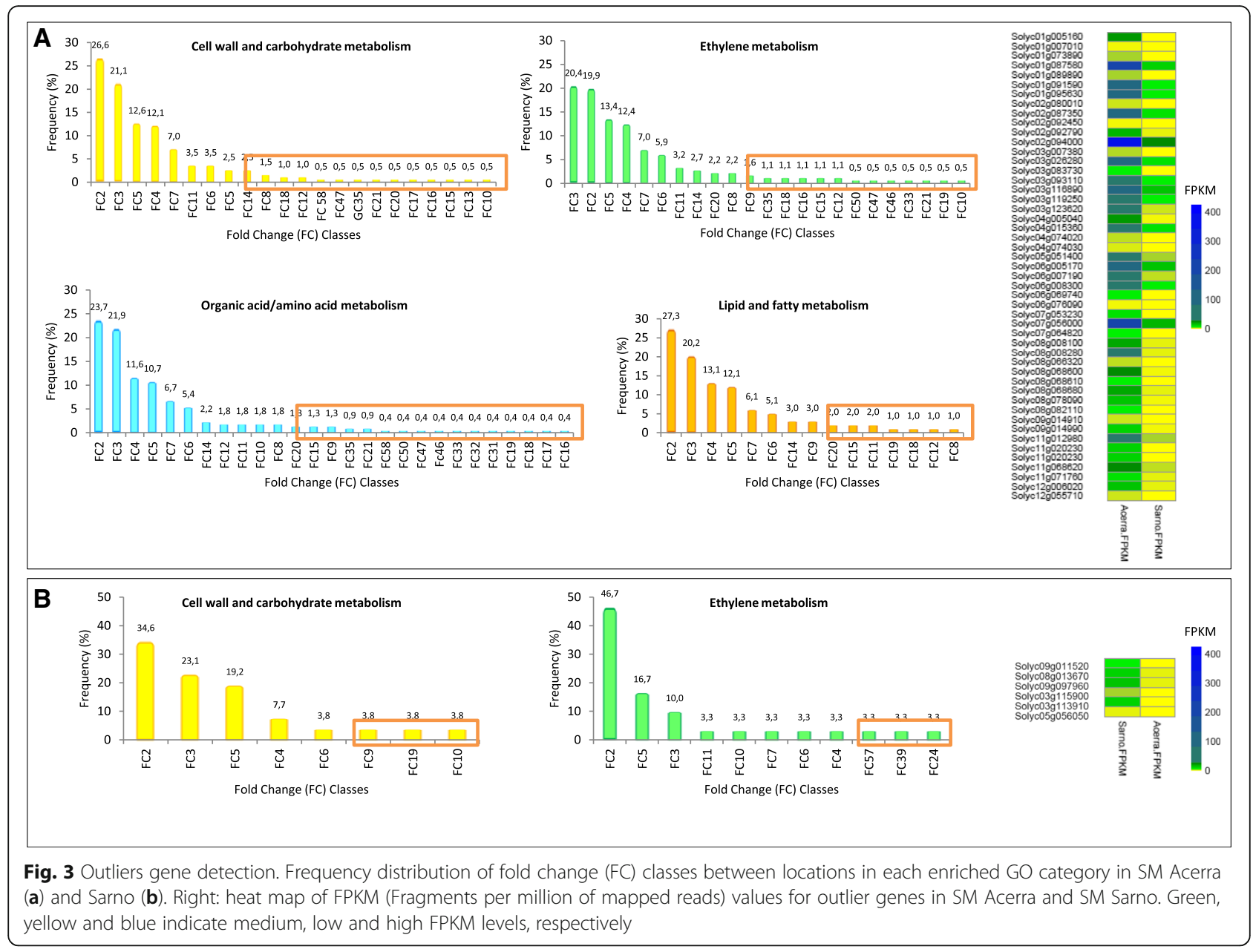

showed significant differences according to the environment (E) or genotype (G) effect.

The PCA plot for each genotype is reported in Fig. 7. For $\mathrm{H}$, the main contributors to total variance between the two environments were tomato flavor, color, juiciness, flouriness and hardness. For SM sensorial attributes contributing to the variance between the two environments were color, color uniformity, odor, turgidity, sourness and saltiness. For RSV, 32.8\% of the total variance was explained by juiciness, flouriness, skin resistance, saltiness, odor and flavor.

\section{Correlation-based network analysis}

We next integrated transcript, metabolite and sensorial data in order to visualize the network of relationships between fields both for SM and RSV. Conserved and environment-specific regulatory paths as well as specific environment interactions were evidenced. Locationspecific hubs included important fruit quality categories, highlighting a strong correlation among different components of fruit metabolism.
In $\mathrm{SM}$, the top $10 \%$ of hubs evidenced in each environment are reported in Additional file 1: Fig. S11. Four common regulatory hubs (Solyc03g093130, Soly c03g094160, Solyc04g071480, Solyc08g007770) were identified (Additional file 1: Fig. S11). Solyc03g093130, an $X T H$ located on chromosome 3, displayed in both environments a positive correlation with the textural attribute hardness as well as with other common regulatory hubs while in Acerra a specific positive correlation was established with turgidity, sourness and juiciness (Fig. 8a). In both environments, Solyc03g093130 showed positive correlations with three other XTHs on chromosome 3 (Solyc03g093080, Solyc03g093110 and Solyc03g093120). By contrast, an XTH located on the chromosome 12 presented specific edges exclusively in Acerra. In Sarno there was a positive correlation of the XTH hub Solyc03g93130 with skin resistance and a negative correlation with juiciness (Fig. 8a). The level of conservation and innovation in terms of edges of the $X T H$ gene family is described in more detail in Fig. 8b. Different genes/isoforms and transcription factors involved in the ethylene biosynthesis also showed to have a dominant role in shaping environment 


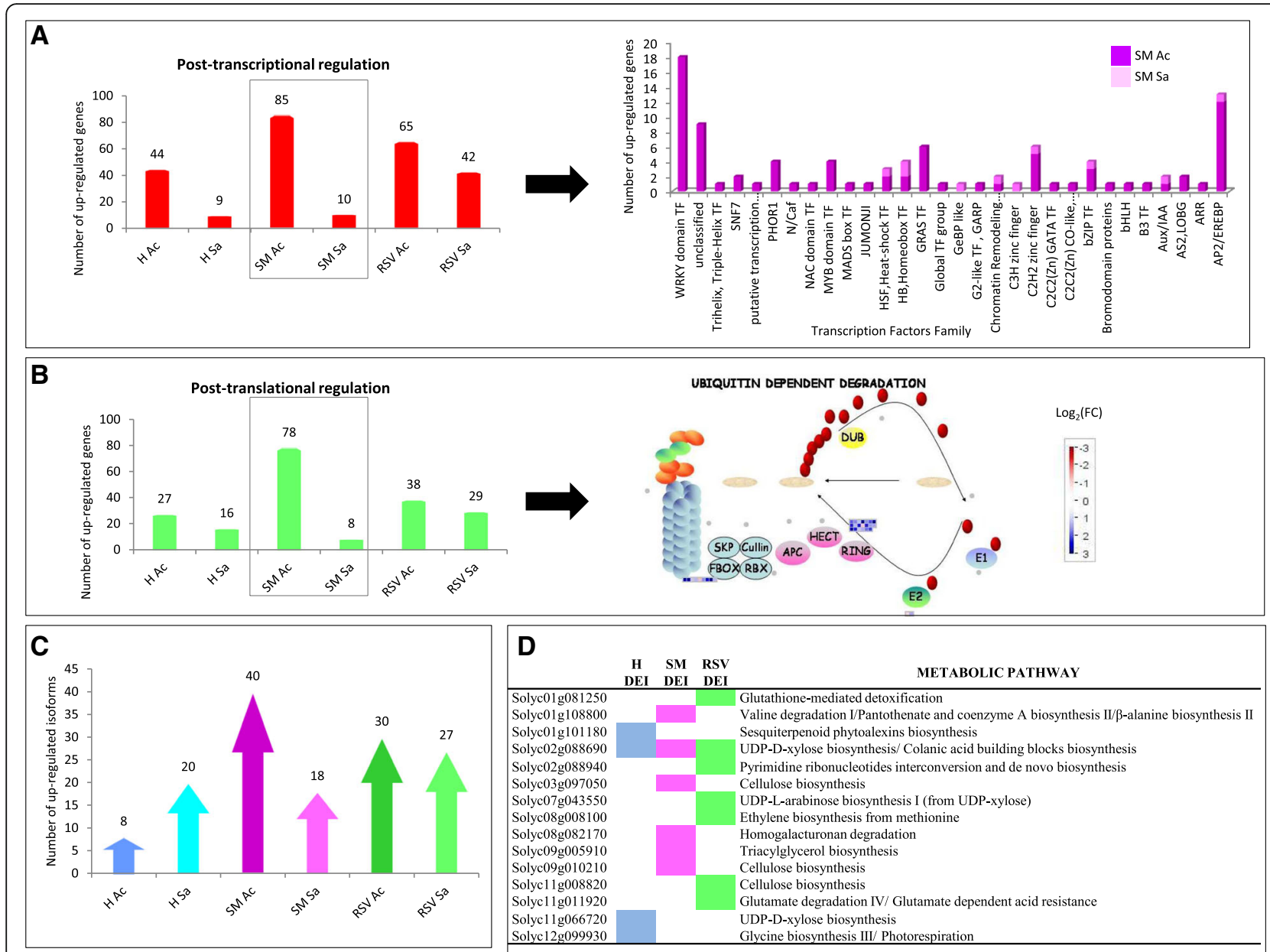

Fig. 4 Molecular regulation of gene expression in SM. a DEGs mapped to the transcriptional regulation process (left). SM DE Transcription factor classification (right). b DEGs mapped to post-translational regulation process (left). SM DEGs mapped to ubiquitin dependent degradation process. c Number of up-regulated isoforms identified in the three genotypes in both locations. $\mathbf{d}$ DEI assigned to fruit quality metabolic pathways in each genotype

response. Solyc08g081540, an 1-Aminocyclopropane-1carboxylic acid synthase 6 (ACS6), in Acerra was negatively correlated with flouriness, red color, sweetness, tomato odor and positively correlated with turgidity juiciness, hardness and sourness and Solyc10g009110, an ethylene responsive factor (ERTFs), was negatively correlated with sweetness, flouriness and red color and positively correlated with sourness, turgidity, juiciness and hardness. In Sarno, a different ACS6 (Solyc08g081550) showed negative correlations with sweetness, saltiness, red color, juiciness and positive correlations with hardness and skin resistance. Solyc10g006130 (ERTF3a) showed negative correlations with hardness, skin, turgidity and positive correlations with red color, saltiness, juiciness, sweetness whilst Solyc03g093540 (ERTF1a) showed a negative correlation with saltiness, red color, sweetness, juiciness and positive correlation with hardness.

In RSV, four common hubs were conserved in both environments (Additional file 1: Figure S12A) and several hubs establish specific correlation, according to the environmental condition. Indeed, Solyc03g093110 was positively correlated with other members of the cluster on chromosome 3 and with the XTH Solyc12g011030 in both environments (Additional file 1: Figure S12B and C) and showed an exclusive positive correlation in Acerra with Solyc07g052980, an XTH that in SM is not differentially expressed. Environmental differences for the hub were related to correlations with taste attributes such as saltiness (positive correlation in Sarno and negative correlation in Acerra), while an exclusive negative correlation was established with skin resistance in Acerra (Additional file 1: Figure S12B). In Acerra, Solyc01g095080, an 1aminocyclopropane-1-carboxylate synthase 2 (ACS2), was negatively correlated with skin resistance, tomato flavor and saltiness and positively correlated with red color, color uniformity and juiciness. Solyc03g093540, an ethylene responsive transcription factor 1a (ERTF1a), showed negative correlations with saltiness, skin resistance and positive 


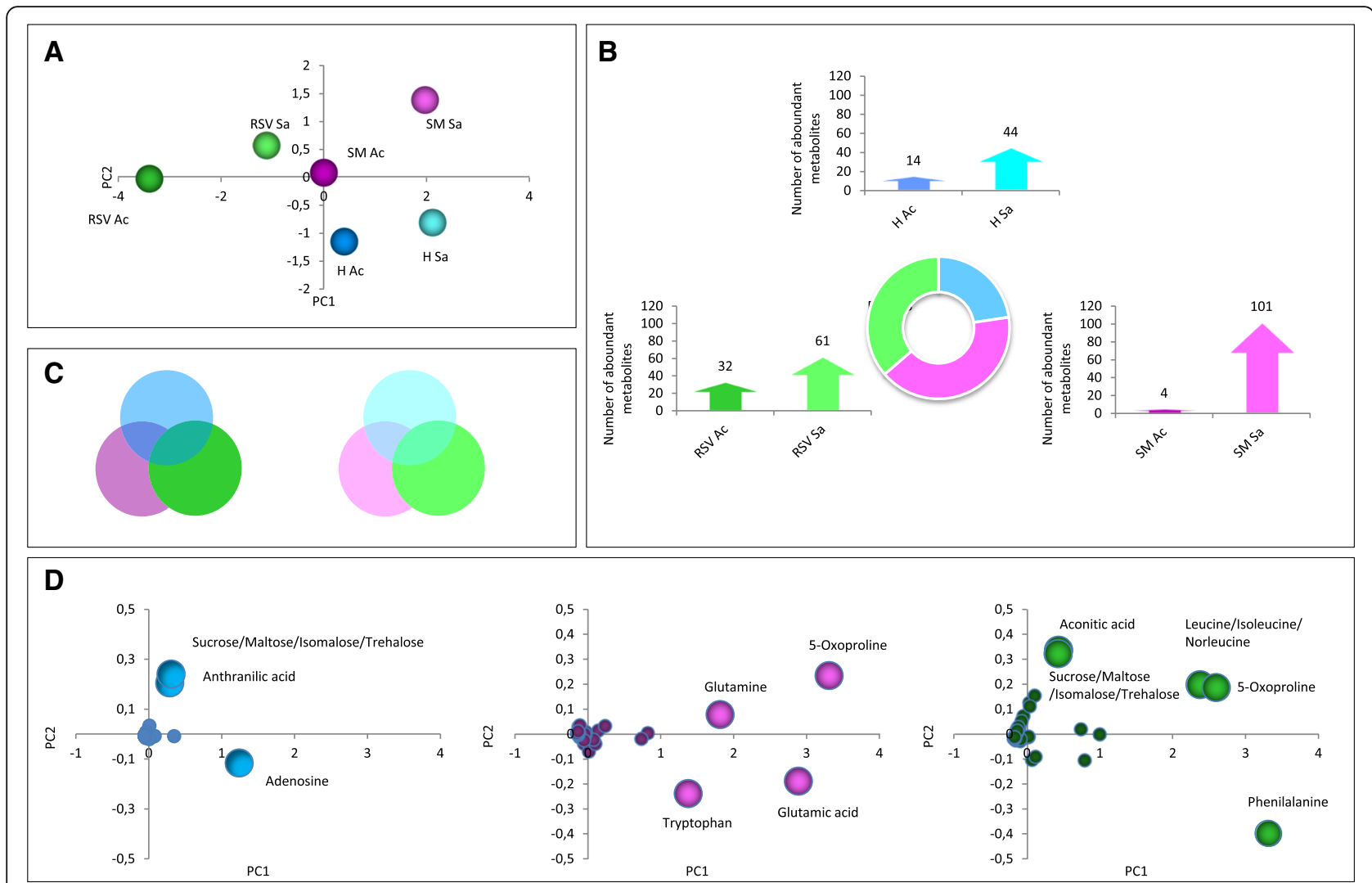

Fig. 5 Changes in metabolic profiles. a Separation of metabolic profiles for each genotype between the two environments. $\mathbf{b}$ Total number of varied metabolites between the two environments for each genotype and distribution of abundant metabolites for each genotype in the two locations. c Number of common varied metabolites in Acerra (Ac) and Sarno (Sa) as well genotypic specific varied metabolites in each localities. d Principal Component Analysis on changed metabolites between the two locations for each genotype ( $\mathrm{H}$ on the left, SM in the middle, RSV on the right)

correlations with red color, color uniformity and juiciness. In Sarno, Solyc12g005940 1-aminocyclopropane-1-carboxylate oxidase 4 (ACO4), was negatively correlated with color uniformity and positively correlated with tomato flavor, sourness, saltiness, turgidity, sweetness and juiciness.

\section{Complex relationships of fruit organoleptic quality attributes}

To further explore the framework of relationships established and to analyze metabolic routes challenged, we extracted sub-networks of key genes and metabolites related to fruit quality attributes.

In the SM sub-network related to appearance a contrasting regulation (positive regulation in $\mathrm{Sa}$ and negative regulation in Ac) of carotenoids pigments with a red color attribute was evidenced (Additional file 1: Figure S13). The $\beta$-carotene hydroxylase transcript (Solyc03g007960) was expressed at low level in Sarno and was negatively correlated with $\beta$-carotene accumulation as expected by the challenging of related pathway (Table 2). In fact, this gene encodes for an enzyme that, in the pathway of zeaxanthin biosynthesis, is involved in the conversion of $\beta$-carotene in $\beta$-criptoxanthin and then in zeaxanthin. Also the four XTHs, clustering on chromosome 3, negatively correlated with red color and three of these (Solyc03g093080, Solyc03g093110 Solyc03g093120), expressed at the higher level in Acerra (Fig. 10), are exclusive to Sa. Fruit texture attributes such as juiciness, hardness, skin resistance, flouriness and turgidity were highly influenced by the environment (Additional file 1: Figure. S14). Interestingly, the transcript levels of 4coumarate CoA ligase-like protein (Solyc06g035960) in Sarno negatively correlated with the accumulation of caffeic acid, ferulic acid and glycosylated forms of coumaric acid and positively correlated with turgidity, skin resistance and hardness (Table 2). Indeed, the downregulation of such enzyme, in suberin and flavonoid biosynthesis, promotes the conversion of caffeate in caffeoylCoA and ferulate in feruloylCoA. SM in Sarno showed a strong positive correlation between a down-regulated decarboxylase (Solyc08g068680), involved into the 2phenylethanol pathway, and two additional decarboxylase genes belonging to the same chromosome region (Fig. 9). 


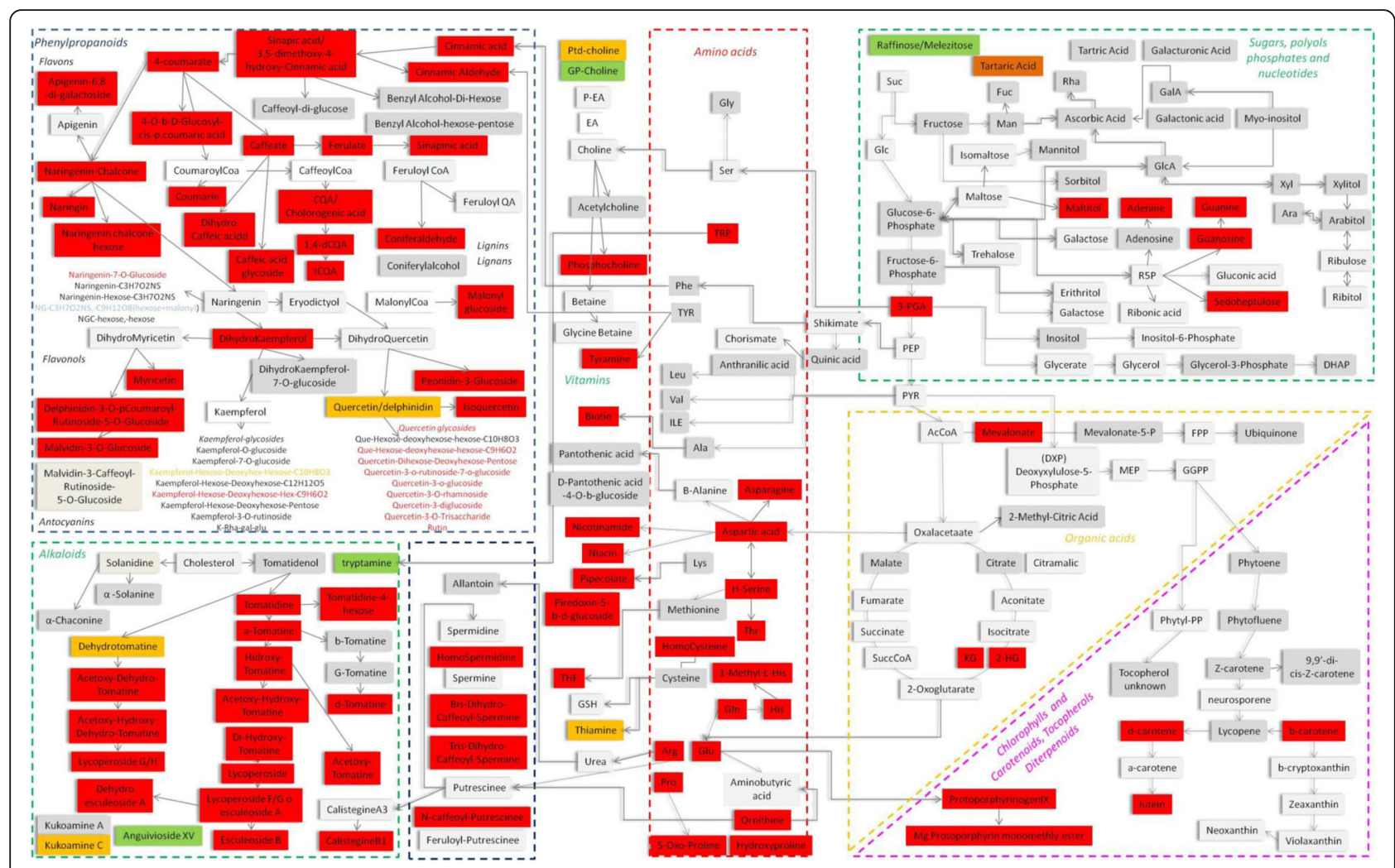

Fig. 6 Schematic representation of the changes in metabolic content between Acerra and Sarno in SM fruits. Red = increased level in Acerra. Green $=$ increased level in Sarno. Gray $=$ not changed. Blue $=$ only present in Acerra. Orange $=$ only present in Sarno. White $=$ not measured. Similar representations for $\mathrm{H}$ and RSV are shown in Figs $\mathrm{S} 9$ and $\mathrm{S} 10$

All three shared a positive correlation with arogenate/prephenate dehydratase and two carbohydrate genes and negative correlations with amino acids (aspartate, proline, 5-oxoproline and histidine). Interestingly, in Sarno there was a direct relationship between the transcript levels of Solyc08g079750 confirmed by Real time PCR (Fig. 10), with the L-aspartate content and saltiness (Table 2) and a negative relationship between tyramine accumulation and an $\mathrm{N}$-acetyltransferase (Solyc08g068690), involved in the pathway of tyramine degradation (Table 2), present at 2 fold lower in Sarno (Fig. 10). At the same time the downregulation of glutamate decarboxylase (Solyc04g025530) correlated well with the high level of glutamic acid in Sarno (Table 2). The enzyme is involved, in fact, in the degradation of glutamate in 4-aminobutyrate. The increase in arginine levels in Sarno is related to the down-regulation of two arginine decarboxylase transcripts (Solyc10g054440, Solyc01g110440) involved in

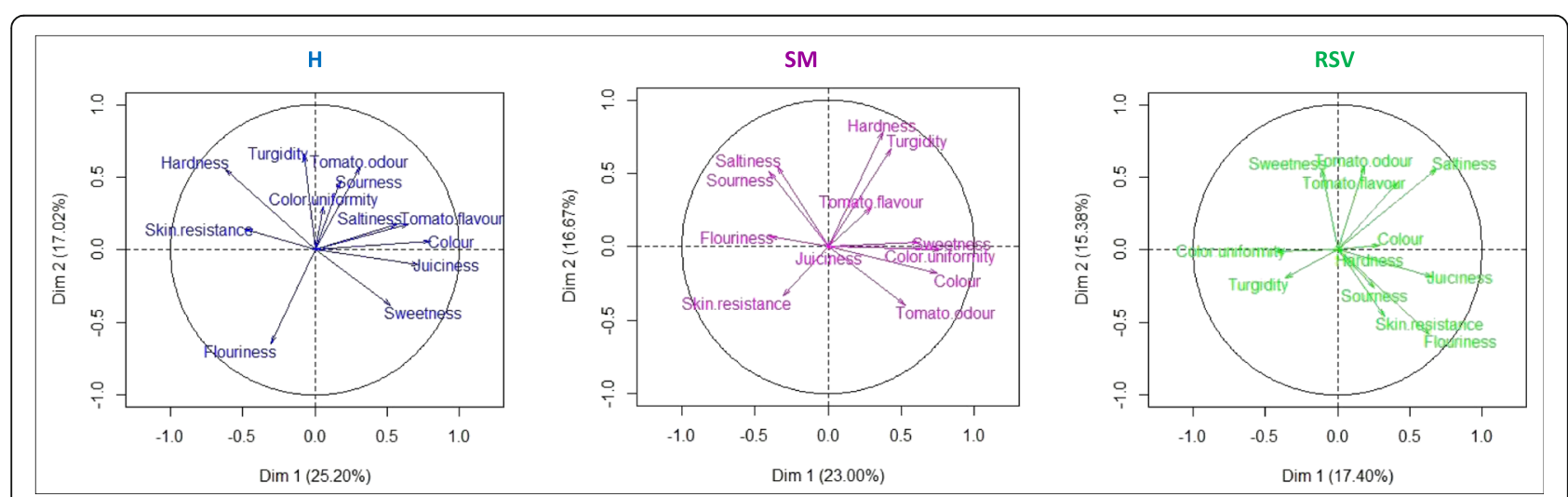

Fig. 7 Changes in sensorial attributes. Principal component analysis (PCA) showing dimension parameters (Dim) 1 and 2 for all fruit quality attributes with projection of sensory descriptors for each genotype 


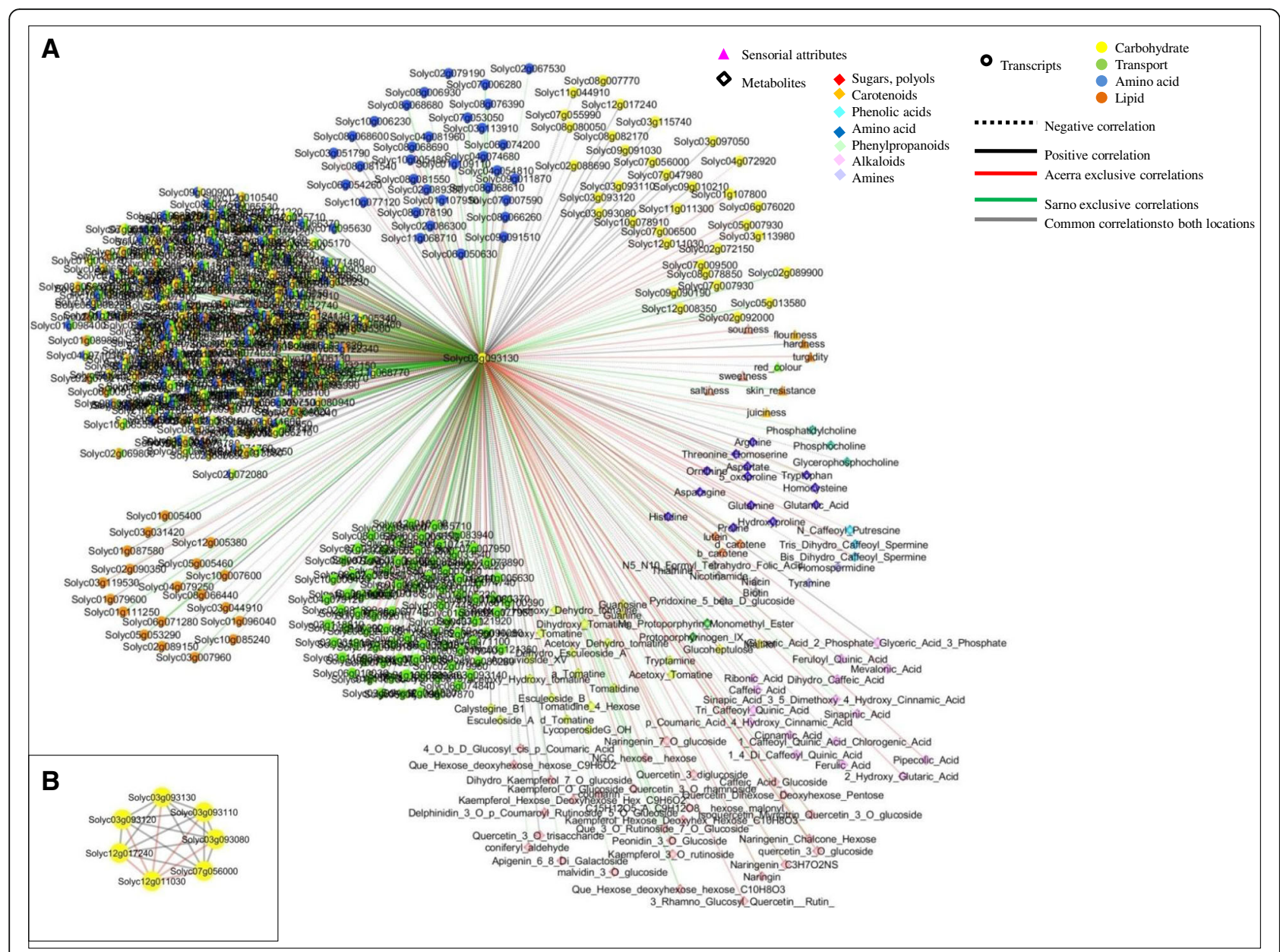

Fig. 8 Network analysis of E effects on SM. a Xyloglucan endotransglucosylase/hydrolase 9 (Solyc03g093130) sub-network. b Xyloglucan endotransglycosylase family network

Table 2 Relationships between transcripts, metabolite abundance and sensorial attributes in SM

\begin{tabular}{|c|c|c|c|c|}
\hline DE transcript & Related pathway & $\begin{array}{l}\text { Related } \\
\text { changed } \\
\text { metabolites }\end{array}$ & $\begin{array}{l}\text { Related network correlations: } \\
\text { Sarno }\end{array}$ & $\begin{array}{l}\text { Related network } \\
\text { correlations: Acerra }\end{array}$ \\
\hline $\begin{array}{l}\text { Solyc10g054440-Arginine } \\
\text { decarboxylase }\end{array}$ & Arginine degradation & L-Arginine & $\begin{array}{l}\text { (+) Sourness; (-) Flavor; } \\
(-) \text { Solyc01g110440 }\end{array}$ & (+) Sourness; (+) Saltiness \\
\hline $\begin{array}{l}\text { Solyc01g1 10440-Arginine } \\
\text { decarboxylase }\end{array}$ & Arginine degradation & L-Arginine & $\begin{array}{l}\text { (-) Sourness; (-) Arginine; } \\
\text { (-) Solyc10g05444 }\end{array}$ & $\begin{array}{l}\text { (+) Flavor; (+) Sweetness; } \\
\text { (-) Arginine }\end{array}$ \\
\hline Solyc08g079750 a & TCA cycle variation 4 & L-Aspartate & (-) Saltiness;(-) Sweetness; & (-) Sweetness \\
\hline $\begin{array}{l}\text { Solyc04g025530-Glutamate } \\
\text { decarboxylase }\end{array}$ & Glutamate degradation & L-Glutamate & (-) Flavor; (+) Saltiness & $\begin{array}{l}\text { (+) Flavor } \\
(+) \text { Glutamic acid }\end{array}$ \\
\hline $\begin{array}{l}\text { Solyc06g035960-4- } \\
\text { Coumarate-CoA ligase-like } \\
\text { protein }\end{array}$ & $\begin{array}{l}\text { Suberin/Flavonoid } \\
\text { biosynthesis }\end{array}$ & $\begin{array}{l}\text { Caffeate } \\
\text { 4-Coumarate } \\
\text { Ferulate }\end{array}$ & $\begin{array}{l}\text { (-) Caffeate; (-) Ferulate; } \\
(-) \text { Glycosylated coumaric acid; } \\
\text { (+) Skin resistance; (+) Hardness; } \\
\text { (+) Color uniformity; (+) Turgidity }\end{array}$ & $\begin{array}{l}\text { (-) Skin resistance;(-) Turgidity;(+) } \\
\text { Caffeate; }(-) \text { Color uniformity }\end{array}$ \\
\hline $\begin{array}{l}\text { Solyc08g068690-N- } \\
\text { Acetyltransferase }\end{array}$ & $\begin{array}{l}\text { Hydroxycinnamic acid/ } \\
\text { Tyramine amides } \\
\text { biosynthesis }\end{array}$ & Tyramine & $\begin{array}{l}\text { (-) Tyramine; (-) Juiciness; } \\
\text { (+) Hardness; (+) Turgidity; } \\
\text { (+) Skin resistance }\end{array}$ & $\begin{array}{l}\text { (+) Hardness; (+) Turgidity;(+) } \\
\text { Juiciness; } \\
\text { (-) Tyramine }\end{array}$ \\
\hline $\begin{array}{l}\text { Solyc03g007960 } \\
\beta \text {-Carotene hydroxylase2 }\end{array}$ & Zeaxanthin biosynthesis & $\beta$-carotene & (-) Red color; (-) $\beta$-carotene & \\
\hline
\end{tabular}



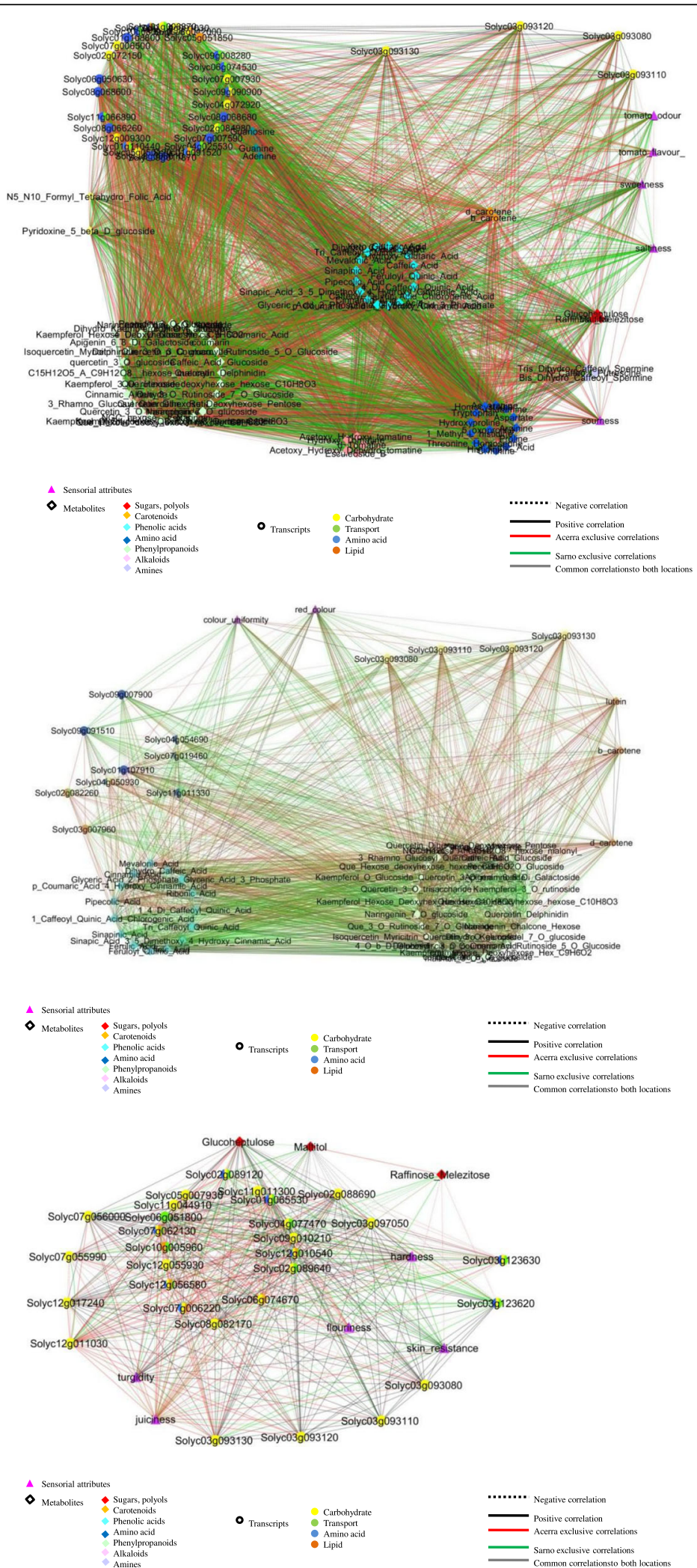

Fig. 9 Sensory attribute-specific network analysis of SM. Flavor and aroma sub-network 


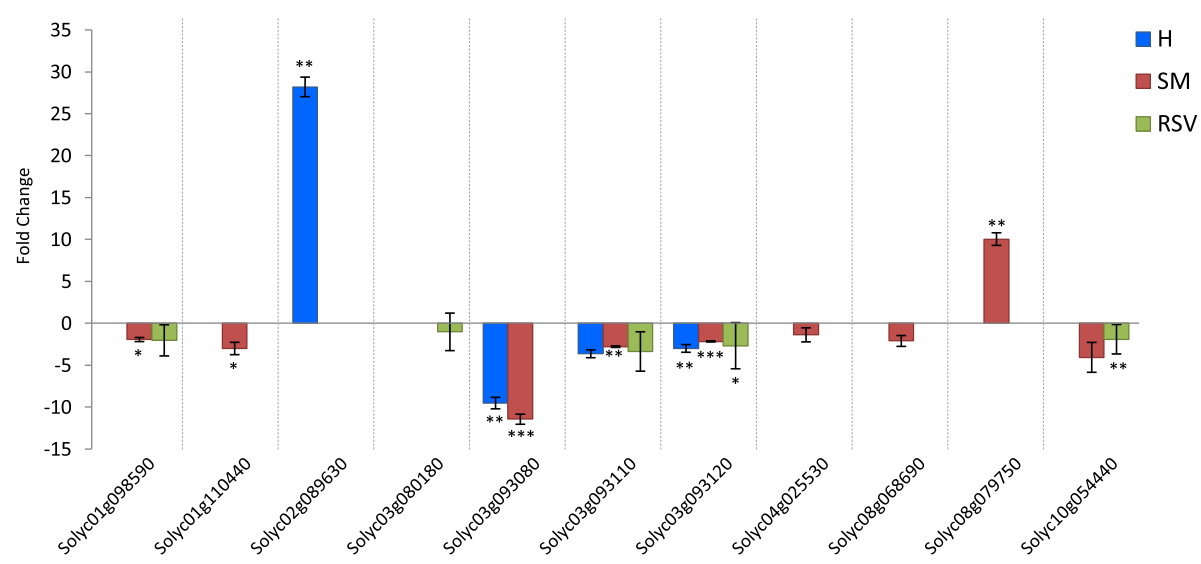

Fig. 10 Quantitative real-time RT-PCR (qPCR) analysis. San Marzano variety (SM) responsive genes involved in fruit quality pathways. The expression level of each gene is normalized by using a reference gene, Elongation Factor and then calculated as relative level in Sarno to in Acerra (control). qPCR data are presented as means \pm SD for three biological replicates

arginine degradation (Fig. 10). Arginine decarboxylase (Solyc01g110440) had a negative correlation with sourness in Sarno and a positive correlation with flavor and a negative correlation with arginine in Acerra. (Table 2).

As for RSV, (Additional file 1: Figure S15A) the red color resulted negatively correlated with kaempferol and naringenin in Sarno and positively correlated with two XTHs on chromosome 3 in Sarno and one in Acerra. Color uniformity correlated with phytoene and phytofluene, naringenins and chromosome $3 X T H s$ in Acerra. Negative relationships among $X T H s$, hardness and skin resistance in Acerra were evidenced (Additional file 1: Figure S15B). The last attribute was also positively correlated with raffinose, phenolic acids and caffeic acid present at higher levels in this environment. On the other hand, in Sarno such metabolites positively correlated with turgidity. In general, strong cell wall remodeling was evident in RSV with hardness and skin resistance more highly interconnected in Acerra (20 and 30 specific correlations respectively) and turgidity and juiciness in Sarno (35 and 22 specific correlations respectively). In Acerra, flavor was negatively correlated with $X T H s$, most of the amino acids (except proline, alanine and cysteine) and with arginine decarboxylase (Solyc10g054440), which also displayed a negative correlation with arginine accumulation and specific correlations with saltiness and sweetness in Sarno and with sourness and tomato odor in Acerra (Additional file 1: Figure S15C). A positive correlation with valine levels and branched chain amino acid aminotransferase (Solyc03g043880), involved in valine biosynthesis, was found in Acerra. This transcript was also correlated with sweetness, saltiness and flavor, with organic acids and mevalonate in Acerra and with sweetness, sourness, odor and XTHs in Sarno.

\section{Discussion}

Different genomic dynamics shape genotype reaction to the environment

Transcriptome remodeling entailed the coordinate regulation of several hundreds of genes, with different genotypes showing a different responsiveness to different environments, suggesting a their specific sensitivity to external environmental inputs. The vast majority of transcriptional responses to the two environments $(60-70 \%)$ were genotype-specific, indicating a strong $\mathrm{G}$ component in the responses to E. The two "local" genotypes showed a consistently higher numbers of genes which were differentially expressed between the two environments with respect to the reference one (801 in SM and 864 in RSV, compared to 595 in $\mathrm{H}$ ) with a more asymmetric responses between the two environments. In addition, $\mathrm{H}$ showed a higher number of core expressed genes in both locations.

Some processes were regulated independently of the genotype, whilst others were genotype-specific. In Sarno, genotype-independent over-represented categories included genes related to amino acid biosynthesis (serine and cysteine), while genes involved in cell wall, ethylene, methionine and aspartate metabolism were highly regulated in Acerra. Some of these amino acids are known to influence flavor, for instance, cysteine and methionine derivatives are essential flavor components in several plant matrixes [36-38] while aspartate, together with glutamate, is a component of umami taste [39]. Ethylene and cell wall metabolism, on the other hand, are well known to influence another important organoleptic characteristic of tomato fruits i.e. firmness [40].

The effect of different environments on SM and RSV transcriptome is clearly stronger, with a larger number of transcripts being differentially expressed with a wider fold change. Indeed, genes that showed marked environmental 
changes (defined as "outliers") are presumable important for overall fruit quality, since their enzymatic activities (glycosyltransferase, pectinesterases, xyloglucan endotransglycosylase, hydrolases etc.) impact upon similar fruit quality attributes. The resilience of $\mathrm{H}$ to different environments can be attributed to a robust core gene set and an overall low number of DEG between the two environments, but also to the involvement of fewer trans-acting transcription factors in responses to Environment. Proper control of gene expression by transcription factors is critical for the capacity of an organism to respond to changing environments $[41,42]$. This observation suggests that transcriptional regulatory cascades may be key components of differential resilience shown by different plant varieties to changing environmental conditions.

Genome structure and gene organization have a pivotal role in shaping fruit metabolism and its regulation by endogenous and environmental stimuli, resulting in distinctive fruit quality attributes. Albeit some of the previously identified SM- and RSV-specific variants [20] contributed to the differential expression, the vast majority of genes differentially expressed in the two environments were devoid of such variants, indicating that differential responses to environment were modulated by the overall genetic composition of each genotype, acting in trans, rather than by specific structural variants, acting in cis.

Among the DEGs we found a large percentage of genes present in multiple copies. Differential expression of different "subsets" of multi copy genes can generate large changes in environmental sensitivity [43]. The variable transcript accumulation of duplicated genes allows a vast diversity of metabolites to be generated, providing the opportunity for tuning fruit quality attributes by differential gene expression, to fulfill different requirements [44]. The fact that not all annotated genes with the same functions are DEGs, indicates a possible different/essential role for these genes in response to environment.

\section{Overall metabolism activity is controlled by key environmental responsive pathways}

The cultivation of the three genotypes in different environments also led to a severe reprogramming of the fruit metabolite profile. Similar to what observed for transcriptional responses, also metabolic responses to different environments were highly genotype-specific. Metabolite composition is a key factor of fruit quality both with respect to flavor and nutritional quality, determining the palatability of the fruit [45]. Among all metabolites, amino acids, sugars and secondary metabolites proved to be more responsive to the environmental change. Free amino acids may play the role of taste enhancement since the concentration levels of these molecules may significantly affect tomato flavor [19]. The major changes in SM in the level of glutamic acid together with glutamine, aspartic acid and $\gamma$-aminobutyrric acid between the two environments suggest a strong alteration in fruit taste. Glutamic acid, as well as other amino acids (glutamine, aspartic acid) affecting the tomato taste [46], displayed higher concentration in SM fruits harvested in Sarno than in Acerra. Among sugars, raffinose, a sucrose derivate involved in cell wall component biosynthesis, was abundant in Acerra in all three genotypes. Raffinose is metabolized in sink tissues, such as fruit, to release sucrose used for cellulose and cell wall biosynthesis [47]. Remodeling of cell wall metabolism could be related to the difference in texture observed between the two locations. The increase in sucrose observed in Acerra in $\mathrm{H}$ and RSV is related to the decrease in expression of $\beta$-fructofuranosidase insoluble isoenzyme 2 that is involved in the conversion of alpha-Dglucose and D-fructose.

Changes in the levels of xanthophylls and carotenes between environments in there genotypes require a considerable modulation of the "carotenoid pathway". Carotenoids are important not only for fruit color but also for flavor [48] due to the fact that lycopene and $\beta$ carotene are the precursors of many important volatile compounds affecting aroma perception [49, 50]. Flavonoids and phenolic compounds also contribute to the determination of aroma, fragrance, and color. The increased abundance in Sarno of quercetins, kaempferols, naringenins and other phenolic compounds, particularly pronounced in SM, is due an enhancement of the flavonoids and phenylpropanoid pathway related to changes in texture attributes observed between the two fields. In Sarno SM also showed a relevant abundance of glycolakaloids, especially of tomatine and their modified forms, that is correlated with enhanced bitter flavor exhibited in such locations [51].

\section{Investigation of San Marzano contrasting expression and metabolomic pattern}

SM showed an opposite gene expression trend compared to $\mathrm{H}$ and RSV, with fewer up-regulated genes in Sarno than in Acerra. By contrast, the accumulation of metabolites showed a completely different pattern with a higher number of abundant metabolites in Sarno than in Acerra. A possible explanation of these contrasting transcriptomic and metabolomic patterns could be related to a specific adaptation of this variety to a given environment. A superior genotype in one environment may not be superior in a different environment [52]. SM is well adapted to environmental conditions in Sarno, thereby expressing its maximum potential in the environment in question. SM genome showed an enhancement of transcriptional and post-translational events and the presence of a large number of DEIs involved in responses to environmental stimuli, in Acerra. This finding suggests 
that the SM genome requires greater adjustment to respond to new environmental stimuli. By contrast, in Sarno, the niche of origin for the SM ecotype, a low induction of transcription and post-translational events are required. In addition, various metabolic sensing and feedback mechanisms could be able to mediate appropriate responses in crucial cellular processes, such as cell signaling, chromatin structure/function and ultimately gene expression [53].

\section{Shuffling of network relationship under different environmental conditions}

To study the complexity of the concerted action of genes, metabolites and sensorial attributes in a broad perspective we analyzed in depth the framework of relationships established. The relational networks generated showed that several hubs maintained the same interactions in both environments while some edges are gained or lost by one environment to another. In order to better adapt to changing environments, gene expression led to gain or lose interactions and/or change in position in the network underlining different genome response. The gain of an edge between two nodes could be related to the appearance of new functionality. The loss of an edge can result in functional divergence, as when duplicated gene copies lose a subset of interactions [54, 55]. For instance, duplicated genes showing relationships present only in one environment underline the possibility that these genes acquired new functionalities in different environments or suggest a possible sub-functionalization of some duplicated genes. Gene duplication combined with linkage rewiring provides a fundamental engine for diversification of network nodes and edges, though we do not know yet what drives this engine and how the engine works. Indeed, about $50 \%$ of genes included in the networks are duplicated with a different degree among genotypes, including central hubs. Buffering and release of variation is a widespread phenomenon that is caused by incomplete functional redundancy at multiple levels [56]. Unraveling the dynamics, mechanisms, and causes of gene architecture reorganization after duplication is a difficult task. It is possible that retention of gene copies within metabolic networks increases flux providing selective advantage, or maintains gene balance, according to the gene dosage balance hypothesis [54, 57].

Network analysis pointed out the leading role of plant cell wall metabolism in determining quality attributes. In particular, xyloglucan endotransglycosylase/hydrolases emerged as central hubs in the network, being correlated both with other members of the gene family and with sensorial attributes relate to tomato texture and taste. Texture is one of the critical components of tomato fruit quality perception [58]. The activation of genes related to cell wall polysaccharide synthesis affects the structure and properties of cell wall and hence the texture and taste attributes. XTH enzymes are involved in the remodeling of plant cell wall hemicelluloses [59], disassembling of the cellulose-xyloglucan matrix, process that contributes to fruit softening $[60,61]$ or contributing in the maintenance of cell wall integrity [62]. To date, genetically engineered tomatoes with altered expression of xyloglucan endotransglucosylase/hydrolase showed that it affects texture [62-65]. The role of individual cell wall-modifying enzymes in fruit softening and the composition of polymers in the fruit cell wall differ between fruit species and within cultivars of the same species [66]. Important XTH genes, physically located in a cluster on chromosome 3 , display similar expression patterns in all three genotypes and tend to conserve some specific interactions with the other members of the family. On the other hand, few XTHs display specific links only in one environment, suggesting that a cell wall gene remodeling is involved in the adaptation. In tomato the $X T H$ family was highly expanded, suggesting that xyloglucan-modifying enzymes may play a more important role in fruit quality than previously suspected [67].

Network analysis evidenced a multifaceted role of these enzymes: first, they are hubs able to tune network relationships; second, they are involved in regulating different sensory attributes, mainly textural such as flouriness, hardness, turgidity, juiciness and skin resistance, but also related to fruit taste and appearance.

In SM, texture (turgidity and skin resistance) emerged as a highly dynamic sensorial parameter in terms of the number of links between the two environments, including also to the taste attribute saltiness. Also in RSV the textural attributes as well as the taste attribute sweetness were highly dynamic traits, showing a larger number of changing interactions between the two environments. The differential magnitudes in variability of network connectivity (number of links) in changing environment reflect differences in cultivar response to environment (plasticity) deriving from the conservation and divergence of gene regulation in response to different environments. In addition, the ACSs confirm to be master regulators of ethylene biosynthesis and fruit quality [68] as well as the ERF transcription factors, downstream components of ethylene signaling that regulate the expression of ethylene-responsive genes [69,70], which in turn regulate quality related traits, such as color, firmness, aroma, and taste [71-73].

Finally, the combined analysis of rnaseq and metabolome data showed a good correspondence between transcript levels and metabolite abundances. The main pathways related fruit quality showed a coherent pattern between changed metabolites and changed transcripts. Both primary and secondary metabolism changes between Acerra and Sarno resulted from differential gene expression between 
environments. For example, the down regulation in one environment of genes involved in metabolite degradation was consistent with the accumulation of the correspondent metabolite in that environment.

\section{Conclusions}

This work highlights the dual and principal role of the cell wall in fruit quality. The cell wall is the first layer of the fruit to be in contact with the environment. All the quality attributes in the different fields derive from information triggered at the cell wall and affect the metabolism of the fruit and hence quality characteristics including taste perception. Moreover, the ethylene is able to manage a massive surveillance system that affects the cell wall metabolism and texture, but also the accumulation of metabolites related to taste and aroma. The scenario emerging from this analysis provided also an idea of the buffering role to environment changes offered by duplicated genes that can establish various numbers of connections, gain or loss of links as well as emergence of common and environment-specific hubs. Although activate the same fruit processes, mainly represented by cell wall biosynthesis, carbohydrate metabolism and secondary metabolism, tomato plants growing in different environments, follow different transcriptome, metabolome and sensorial trajectories depending on their own genetic makeup. The genotypic resilience to changing environmental conditions is mediated a robust core gene expression dataset and by a proper control of gene expression. Such finding provides a significant advances in general understanding of genome plasticity. A topic that has an increasing importance to agriculture given the current climatic change challenge.

\section{Additional files}

Additional file 1: Table S1. lists the primer sequences used for RTqPCR. Table S2. summarizes RNA sequencing and mapping statistics. Table S3. lists SM and RSV specific DEGs with variants. Table S4. Table S5. and Table S6. show fruit quality genes with high expression ratio and outlier behavior identified in the three tomato genotypes in the two environments. Table S7. shows two-factor analysis of variance (ANOVA) for sensorial attributes. Figure S1. show tomato fruits of the three cultivars at harvesting time. Figure $\mathbf{S 2}$. shows gene expression profiles in the three tomato genotypes. Figure S3. and Figure S4. show Heinz and RSV Gene Ontology Enrichment Analysis. Figure S5. shows genotype $x$ environment enriched GO. Figure S6. shows post-transcriptional regulation in the three genotypes in the two environments. Figure S7. shows the distribution of DEGs in multi-copy gene families. Figure $\mathbf{S 8}$. shows the changes in metabolite profiles between genotypes (H vs SM, H vs RSV and RSV vs SM) for each environment. Figure S9. And Figure S10. show a schematic representation of the changes in metabolic content between Acerra and Sarno in Heinz and RSV fruits. Figure S11. shows SM hubs. Figure S12. shows the use of network hubs in different environmental conditions in RSV. Figure S13. and Figure S14. show SM fruit appearance and texture subnetworks. Figure S15. shows changes in RSV in transcripts, metabolites and sensorial attribute correlations in the two environments. (DOCX $2681 \mathrm{~kb}$ )

Additional file 2: Dataset S1-S4. list Pearson's correlations between transcripts, metabolites and sensorial profiles in SM and RSV in the two environments. Dataset S5., Dataset S6. and Dataset S7. show the novel genes identified in $\mathrm{H}, \mathrm{SM}$ and RSV with relative functional annotation. Datasets S8-S13. list the Gene ontology enrichment analysis for the upregulated genes in $\mathrm{H}, \mathrm{SM}$ and RSV in the two environments. Dataset S14. and Dataset S15. show aboundance measurements of semi-polar and non polar metaboplites in the three tomato genotypes in the two environments. (XLSX 13074 kb)

\section{Abbreviations}

Ac: Acerra; ACO: 1-aminocyclopropane-1-carboxylate oxidase; ACS: 1aminocyclopropane-1-carboxylate synthase, AS: alternative splicing; ANOVA: Analysis of variance; Bp: Base pairs; DEGs: Differentially expressed genes; DEls: Differentially expressed isoforms; Dim: Dimension parameters; E: Environment; ERF: Ethylene-responsive transcription factor; ESI: Electrospray ionization; EXO: Exocyst complex protein EXO70; FC: Fold change; FPKM: Fragments per million of mapped reads; $G \times E$ : Genotype $\times$ environment; G: Genotype; GASA2: Gibberellin-regulated protein 2; GO: Gene Ontology; H: Heinz 1706; LC-APCI-MS: Liquid chromatography -Atmospheric pressure chemical ionization- mass spectrometry; LC-ESI-MS: Liquid chromatography-electrospray ionization- mass spectrometry; LHC: Chlorophyll a/b binding protein; LOX: Lipoxygenase; MLP: Major latexlike protein; MORC: MORC family CW-type zinc finger 3; MSP: Male sterility 5 family protein; Ole e 1: Pollen Ole e 1 allergen and extensin;

PAL: Phenylalanine ammonia-lyase; PCA: Principal component analysis; PDA: Photodiode array detector; PPase: Pyrophosphate-energized proton pump; PUB: U-box domain-containing protein; PUB15: U-box domaincontaining protein 15; RABT: Reference annotation based assembly; RSV: Vesuviano; Sa: Sarno; SM: San Marzano; XPR1: Xenotropic and polytropic retrovirus receptor; XTHs: Xyloglucan endotransglycosylase hydrolases

\section{Acknowledgements}

The authors wish to thank Mark Walters for editing the manuscript.

\section{Funding}

This work was supported by the Italian Ministry of University and Research (GenoPOM-pro project), by the EU-H2020 project - TRADITOM", contract no. 634561, EU-H2020 project TOMgem, contract no.679796, the COST Action FA1106 (QualityFruit) and Action CA15136 (EUROCAROTEN).

\section{Availability of data and materials}

Sequence data that support the findings of this study have been deposited in the permanent public repository Gene Expression Omnibus (GEO) with the following series accession number GSE75273.

\section{Authors' contributions}

DD analyzed data, interpreted results and wrote the article. FF performed field experiments and RNA extraction for sequencing. ADM and AM performed RNA sequencing and trascriptome reconstruction under the supervision of MD. GD performed the metabolomic analysis. GG supervised metabolomic analysis and critically revised the manuscript. AS performed RNA extraction and $\mathrm{qPCR}$. AB was involved in field experiments and provided a critical review of the manuscript. RDM and SC performed sensorial analysis. LT provided statistical support for the data analysis. LF was involved in experimental planning and results interpretation. MRE conceived the overall study and co-wrote the paper. All authors read and approved the final manuscript.

\section{Competing interests}

The authors declare that they have no competing interests.

\section{Consent for publication}

Not applicable.

Ethics approval and consent to participate Not applicable.

\section{Author details}

'Department of Agricultural Sciences, University of Naples Federico II, Portici 80055, Italy. ${ }^{2}$ Department of Biotechnologies, Functional Genomics Center, University of Verona, Verona 37134, Italy. ${ }^{3}$ Italian National Agency for New Technologies, Energy and Sustainable Development (ENEA), Casaccia 
Research Center, Rome 00123, Italy. ${ }^{4}$ Department of Statistical Sciences, University of Rome 'La Sapienza', Rome 00185, Italy.

\section{Received: 14 October 2016 Accepted: 27 February 2017 Published online: 28 March 2017}

\section{References}

1. Pigliucci M. Modelling phenotypic plasticity. II. Do genetic correlations matter? Heredity. 1996;77:453-60.

2. DeWitt TJ, Sih A, Wilson DS. Costs and limits of phenotypic plasticity. Trends Ecol Evol. 1998:13:77-81.

3. Schlichting $C D$, Smith $H$. Phenotypic plasticity: linking molecular mechanisms with evolutionary outcomes. Evol Ecol. 2002;16:189-211.

4. de Jong G. Evolution of phenotypic plasticity: patterns of plasticity and the emergence of ecotypes. New Phytol. 2005;166:101-18.

5. Jump AS, Peñuelas J. Running to stand still: Adaptation and the response of plants to rapid climate change. Ecol Lett. 2005;8:1010-20.

6. Soudzilovskaia NA, Elumeeva TG, Onipchenko VG, Shidakov II, Salpagarova FS, Khubiev AB, Tekeev DK, Cornelissen JHC. Functional traits predict relationship between plant abundance dynamic and long-term climate warming. Proc Natl Acad Sci U S A. 2013;110:18180-4.

7. Jung V, Albert $\mathrm{CH}$, Violle C, Kunstler G, Loucougaray G, Spiegelberger T. Intraspecific trait variability mediates the response of subalpine grassland communities to extreme drought events. J Ecol. 2014;102:45-53.

8. Franks SJ, Weber JJ, Aitken SN. Evolutionary and plastic responses to climate change in terrestrial plant populations. Evol Appl. 2014;7:123-39.

9. Frei ER, Ghazoul J, Matter P, Heggli M, Pluess AR. Plant population differentiation and climate change: Responses of grassland species along an elevational gradient. Glob Chang Biol. 2014;20:441-55.

10. Warren IA, Ciborowski KL, Casadei E, Hazlerigg DG, Martin S, Jordan WC Sumner S. Extensive local gene duplication and functional divergence among paralogs in Atlantic salmon. Genome Biol. Evol. 2014;6:1790-805.

11. Prasanna V, Prabha TN, Tharanathan RN. Fruit ripening phenomena: an overview. Crit Rev Food Sci Nutr. 2007:47:1-19.

12. Defilippi BG, Manriquez D, Luengwilai K, Gonzalez-Aguero M. Aroma volatiles: biosynthesis and mechanisms of modulation during fruit ripening. Adv Bot Res. 2009:50:1-37.

13. Bovy A, Schijlen E, Hall RD. Metabolic engineering of flavonoids in tomato Solanum lycopersicum): the potential for metabolomics. Metabolomics. 2007;3:399-412.

14. Fraser PD, Enfissi EMA, Halket JM, Truesdale MR, Yu D, Gerrish C, Bramley P. Manipulation of phytoene levels in tomato fruit: effects on isoprenoids, plastids, and intermediary metabolism. Plant Cell. 2007;19:3194-211.

15. Vicente AR, Saladie M, Rose JKC, Labavitch JM. The linkage between cell wall metabolism and fruit softening: looking to the future. J Sci Food Agric. 2007;87: 1435-48.

16. Causse M, Buret M, Robini K, Verschave P. Inheritance of nutritional and sensory quality traits in fresh market tomato and relation to consumer preferences. J Food Sci. 2003;68:2342-50.

17. Enfissi EMA, Fraser PD, Bramley PM. Genetic engineering of carotenoid formation in tomato. Phytochem Rev. 2006;5:59-65.

18. Ercolano MR, Carli P, Soria A, Cascone A, Fogliano V, Frusciante L, Barone A. Biochemical, sensorial and genomic profiling of traditional Italian tomato varieties. Euphytica. 2008;164:571-82.

19. Carli P, Barone A, Foglian V, Frusciante L, Ercolano MR. Dissection of genetic and environmental factors involved in tomato organoleptic quality. BMC Plant Biol. 2011;11:58.

20. Ercolano MR, Sacco A, Ferriello F, D' Alessandro R, Tononi P, Traini A, Barone A, Zago E, Chiusano ML, Buson G, Delledonne M, Frusciante L. Patchwork sequencing of tomato San Marzano and Vesuviano varieties highlights genome-wide variations. BMC Genomics. 2014;15:138

21. Loiudice R, Impembo M, Laratta B, Villari G, Lo Voi A, Siviero $P$, Castaldo D. Composition of San Marzano tomato varieties. Food Chem. 1995;53:81-9.

22. Parisi M, Pentangelo A, D'Onofrio B, Villari G, Giordano I. Studi su ecotipi campani di pomodorino "Corbarino" e "Vesuviano" in due ambienti. ItalusHortus. 2006;13:775-8.

23. Weckwerth W. Integration of metabolomics and proteomics in molecular plant physiology - Coping with the complexity by data-dimensionality reduction. Physiol Plant. 2008;132:176-89.
24. Wang HM, Yin WC, Wang CK, To KY. Isolation of functional RNA from different tissues of tomato suitable for developmental profiling by microarray analysis. Bot Stud. 2009;50:115-25.

25. Wang L, Wang S, Li W. RSeQC: quality control of RNA-seq experiments. Bioinformatics. 2012;28(16):2184-5.

26. Roberts A, Pimentel $H$, Trapnell $C$, Pachter $L$. Identification of novel transcripts in annotated genomes using RNA-seq. Bioinformatics. 2011;27:2325-9.

27. Trapnell C, Roberts A, Goff L, Pertea G, Kim D, Kelley DR, Pimentel H, Salzberg SL, Rinn JL, Pachter L. Differential gene and transcript expression analysis of RNA-seq experiments with TopHat and Cufflinks. Nat Protoc. 2012;7:562-78

28. Livak KJ, Schmittgen TD. Analysis of relative gene expression data using real-time quantitative PCR and the 2(-Delta Delta C(T)) method. Methods. 2001;25:402-8.

29. Conesa A, Götz S, García-Gómez JM, Terol J, Talón M, Robles M. Blast2GO: A universal tool for annotation, visualization and analysis in functional genomics research. Bioinformatics. 2005;21:3674-6.

30. Joung JG, Corbett AM, Fellman SM, Tieman DM, Klee HJ, Giovannoni JJ, Fei Z. Plant MetGenMAP: an integrative analysis system for plant systems biology. Plant Physiol. 2009;151:1758-68.

31. Usadel B, Poree F, Nagel A, Lohse M, Czedik-Eysenberg A, Stitt M. A guide to using MapMan to visualize and compare Omics data in plants: A case study in the crop species. Maize Plant Cell Environ. 2009;32:1211-29.

32. De Vos RC, Moco S, Lommen A, Keurentjes JJ, Bino RJ, Hall RD. Untargeted large-scale plant metabolomics using liquid chromatography coupled to mass spectrometry. Nat Protoc. 2007;2:778-91.

33. lijima $Y$, et al. Metabolite annotations based on the integration of mass spectral information. Plant J. 2008;54:949-62.

34. Liu L, Shao Z, Zhang M, Wang Q. Regulation of carotenoid metabolism in tomato. Mol Plant. 2015:8:28-39.

35. Shannon P, Markiel A, Ozier O, Baliga NS, Wang JT, Ramage D, Amin N, Schwikowski B, Ideker T. Cytoscape : a software environment for integrated models of biomolecular interaction networks. Genome Res. 2003;13:2498-504.

36. Randle WM, Lancaster JE, Shaw ML, Sutton KH, Hay RL, Bussard ML. Studies on the photolysis of I-cysteine and I-cystine: formation of the flavor of cooked rice from I-cysteine and I-cystine. Agric Biol Chem. 1995;29(3):191-5.

37. Tominaga T, Peyrot des Gachons C, Dubourdieu D. A New type of flavor precursors in vitis vinifera L. cv. Sauvignon Blanc: S-cysteine conjugates. J Agric Food Chem. 1998;46(12):5215-9

38. Di R, Kim J, Martin MN, Leustek T, Jhoo J, Ho CT, Tumer NE. Enhancement of the primary flavor compound methional in potato by increasing the level of soluble methionine. J Agric Food Chem. 2003;51(19):5695-702.

39. Zhao GQ, Zhang Y, Hoon MA, Chandrashekar J, Erlenbach I, Ryba NJ, Zuker CS. The receptors for mammalian sweet and umami taste. Cell. 2003;115(3):255-66

40. Seymour GB, Østergaard L, Chapman NH, Knapp S, Martin C. Fruit development and ripening. Annu Rev Plant Biol. 2013;64:219-41.

41. López-Maury L, Marguerat S, Bähler J. Tuning gene expression to changing environments: from rapid responses to evolutionary adaptation. Nat Rev Genet. 2008:9:583-93.

42. Ni F, Chu L, Shao H, Liu Z. Gene expression and regulation of higher plants under soil water stress. Current Genomics. 2009:10:269-80.

43. Hofmann CM, Carleton KL. Gene duplication and differential gene expression play an important role in the diversification of visual pigments in fish. Integr Comp Biol. 2009;49:630-43.

44. Kliebenstein DJ. A role for gene duplication and natural variation of gene expression in the evolution of metabolism. PLoS One. 2008;3:e1838.

45. Snowden CJ, Thomas B, Baxter CJ, Smith JAC, Sweetlove LJ. A tonoplastGlu/ Asp/GABA exchanger that affects tomato fruit amino acid composition. Plant J. 2015;81:651-60.

46. Yamaguchi S, Ninomiya K. The use and utility of glutamates as flavoring agents in food. J Nutr. 2000;130:921-6.

47. Dai N, Petreikov M, Portnoy V, Katzir N, Pharr DM, Schaffer AA. Cloning and expression analysis of a UDP-galactose/glucose pyrophosphorylase from melon fruit provides evidence for the major metabolic pathway of galactose metabolism in raffinose oligosaccharide metabolizing plants. Plant Physiol. 2006;142:294-304.

48. Tohge T, Alseekh S, Fernie AR. On the regulation and function of secondary metabolism during fruit development and ripening. J Exp Bot. 2014;65:4599-611.

49. Vogel JT, Tieman DM, Sim CA, Odabasi AZ, Clark DG, Klee HJ. Carotenoid content impacts flavor acceptability in tomato Solanum lycopersicum. J Sci Food Agric. 2010;90:2233-40. 
50. Liu M, Diretto G, Pirrello J, Roustan J-P, Li Z, Giuliano G, Regad F, Bouzayen $M$. The chimeric repressor version of an ethylene response factor ERF) family member, SI-ERF.B3, shows contrasting effects on tomato fruit ripening. The New Phytologist. 2014;203:206-18.

51. Friedman M. Tomato glycoalkaloids: Role in the plant and in the diet. J Agric Food Chem. 2002;50:5751-80.

52. Panthee DR, River M, Cao C, Debenport SJ, Rodriguez GR, Labate JA, Robertson LD, Breksa AP, Knaap EVD, Gardner BBM. Magnitude of genotype $x$ environment interactions affecting tomato fruit quality. Hort-Sci. 2012;47:721-6.

53. Krejči A. Metabolic sensors and their interplay with cell signalling and transcription. Biochem Soc Trans. 2012;40:311-23.

54. Chae L, Lee I, Shin J, Rhee SY. Towards understanding how molecular networks evolve in plants. Curr Opin Plant Biol. 2012;15:177-84.

55. Reece-Hoyes JS, et al. Extensive rewiring and complex evolutionary dynamics in a C. elegans multiparameter transcription factor network. Mol. Cell. 2013;51:116-27.

56. Levy SF, Siegal ML. Network hubs buffer environmental variation in Saccharomyces cerevisiae. PLoS Bio. 2008;6:e264.

57. De La Torre AR, Lin Y-C, Van de Peer Y, Ingvarsson PK. Genome-wide analysis reveals diverged patterns of codon bias, gene expression, and rates of sequence evolution in picea gene families. Genome Bio Evol. 2015;7:1002-15.

58. Chaïb J, Devaux MF, Grotte MG, Robini K, Causse M, Lahaye M, Marty I. Physiological relationships among physical, sensory, and morphological attributes of texture in tomato fruits. J Exp Bot. 2007;58:1915-25.

59. Nardi CF, Villarreal NM, Opazo MC, Martínez GA, Moya-león MA, Civello PM. Expression of FaXTH1 and FaXTH2 genes in strawberry fruit. Cloning of promoter regions and effect of plant growth regulators. Sci Hortic. 2014;165:111-22.

60. Atkinson RG, Johnston SL, Yauk YK, Sharma NN, Schroder R. Analysis of xyloglucan endotransglucosylase/hydrolase $(\mathrm{XTH})$ gene families in kiwifruit and apple. Postharvest Biol Technol. 2009;51:149-57.

61. Mbéguié-A-Mbéguié $D$, Hubert $O$, Baurens FC, Matsumoto T, Chillet $M$, FilsLycaon B, Sidibé-Bocs S. Expression patterns of cell wall-modifying genes from banana during fruit ripening and in relationship with finger drop. $J$ Exp Bot. 2009;60:2021-34.

62. Miedes E, Herbers K, Sonnewalds U, Lorences EP. Overexpression of a cell wall enzyme reduces xyloglucan depolymerization and softening of transgenic tomato fruits. J Agric Food Chem. 2010;58:5708-13.

63. Brummell DA, Harpster MH, Civello PM, Palys JM, Bennett AB, Dunsmuir P. Modification of expansin protein abundance in tomato fruit alters softening and cell wall polymer metabolism during ripening. Plant Cell. 1999;11:2203-16.

64. Kalamaki MS, Harpster MH, Palys JM, Labavitch JM, Reid DS, Brummell DA. Simultaneous transgenic suppression of LePG and LeExp1 influences rheological properties of juice and concentrates from a processing tomato variety. J Agric Food Chem. 2003;51:7456-64.

65. Powell ALT, Kalamaki MS, Kurien PA, Gurrieri S, Bennett AB. Simultaneous transgenic suppression of LePG and LeEXP1 influences fruit texture and juice viscosity in a fresh market tomato variety. J Agric Food Chem. 2003;51:7450-5.

66. Bonghi C, Manganaris GA. In: Benkeblia N, editor. OMICs Technologies: Tools for Food Science. Boca Raton: CRC Press Taylor \& Francis Group; 2012.

67. Tomato Genome Consortium. The tomato genome provides insights into fleshy fruit evolution. Nature. 2012;485:635-41.

68. Yoon GM, Kieber JJ. 1-Aminocyclopropane-1-carboxylic acid as a signalling molecule in plants. AoB Plants. 2013;5:plt017.

69. Solano R, Stepanova A, Chao Q, Ecker JR. Nuclear events in ethylene signaling: a transcriptional cascade mediated by ETHYLENE-INSENSITIVE3 and ETHYLENE-RESPONSE-FACTOR1. Genes Dev. 1998;12:3703-14.

70. Pirrello J, Prasad BCN, Zhang W, Chen K, Mila I, Zouine M, Latché A, Pech JC, Ohme-Takagi M, Regad F, et al. Functional analysis and binding affinity of tomato ethylene response factors provide insight on the molecular bases of plant differential responses to ethylene. BMC Plant Biol. 2012;12:190.

71. Solano R, Ecker JR. Ethylene gas: perception, signaling and response. Curr Opin Plant Biol. 1998;1:393-8.

72. Ju C, Yoon GM, Shemansky JM, Lin DY, Ying ZI, Chang J, Garrett WM, Kessenbrock M, Groth G, Tucker ML, et al. CTR1 phosphorylates the central regulator EIN2 to control ethylene hormone signaling from the ER membrane to the nucleus in Arabidopsis. Proc Natl Acad Sci U S A. 2012; 109:19486-91.

73. Chang KN, Zhong S, Weirauch MT, Hon G, Pelizzola M, Li H, Huang SS, Schmitz RJ, Urich MA, Kuo D, et al. Temporal transcriptional response to ethylene gas drives growth hormone cross-regulation in Arabidopsis. elife. 2013;2:e00675.

\section{Submit your next manuscript to BioMed Central and we will help you at every step:}

- We accept pre-submission inquiries

- Our selector tool helps you to find the most relevant journal

- We provide round the clock customer support

- Convenient online submission

- Thorough peer review

- Inclusion in PubMed and all major indexing services

- Maximum visibility for your research

Submit your manuscript at www.biomedcentral.com/submit
C Biomed Central 